\title{
Transcriptome sequencing of rhizome tissue of Sinopodophyllum hexandrum at two temperatures
}

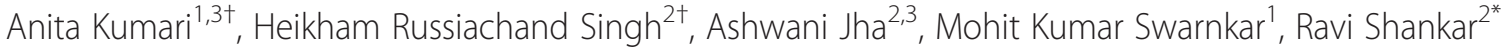 \\ and Sanjay Kumar ${ }^{\text {* }}$
}

\begin{abstract}
Background: Sinopodophyllum hexandrum is an endangered medicinal herb, which is commonly present in elevations ranging between 2,400-4,500 $\mathrm{m}$ and is sensitive to temperature. Medicinal property of the species is attributed to the presence of podophyllotoxin in the rhizome tissue. The present work analyzed transcriptome of rhizome tissue of $\mathrm{S}$. hexandrum exposed to $15^{\circ} \mathrm{C}$ and $25^{\circ} \mathrm{C}$ to understand the temperature mediated molecular responses including those associated with podophyllotoxin biosynthesis.

Results: Deep sequencing of transcriptome with an average coverage of $88.34 \mathrm{X}$ yielded 60,089 assembled transcript sequences representing 20,387 unique genes having homology to known genes. Fragments per kilobase of exon per million fragments mapped (FPKM) based expression analysis revealed genes related to growth and development were over-expressed at $15^{\circ} \mathrm{C}$, whereas genes involved in stress response were over-expressed at $25^{\circ} \mathrm{C}$. There was a decreasing trend of podophyllotoxin accumulation at $25^{\circ} \mathrm{C}$; data was well supported by the expression of corresponding genes of the pathway. FPKM data was validated by quantitative real-time polymerase chain reaction data using a total of thirty four genes and a positive correlation between the two platforms of gene expression was obtained. Also, detailed analyses yielded cytochrome P450s, methyltransferases and glycosyltransferases which could be the potential candidate hitherto unidentified genes of podophyllotoxin biosynthesis pathway.
\end{abstract}

Conclusions: The present work revealed temperature responsive transcriptome of $\mathrm{S}$. hexandrum on Illumina platform. Data suggested expression of genes for growth and development and podophyllotoxin biosynthesis at $15^{\circ} \mathrm{C}$, and prevalence of those associated with stress response at $25^{\circ} \mathrm{C}$.

Keywords: Below ground, Deep sequencing, Development, Gene expression, Growth, Next generation sequencing, Podophyllotoxin, RNA-seq, Stress

\section{Background}

Sinopodophyllum hexandrum (Royle) T.S. Ying, commonly known as Himalayan Mayapple, is an alpine herb of family Berberidaceae that grows on altitudes ranging between $2,400-4,500 \mathrm{~m}$ above mean sea level [1]. The species is a perennial, erect, and unbranched herb reaching to a height of $40-50 \mathrm{~cm}$; rhizome gives rise to multiple stems. Rhizome is non-edible, but is the source of a cytotoxic compound podophyllotoxin which is an aryltetralin lignan. Cytotoxicity

\footnotetext{
* Correspondence: ravish@ihbt.res.in; sanjayplp1@gmail.com

${ }^{\dagger}$ Equal contributors

${ }^{2}$ Studio of Computational Biology \& Bioinformatics, CSIR-Institute of Himalayan Bioresource Technology, PO Box No. 6, Palampur 176061 , Himachal Pradesh, India

'Biotechnology Division, CSIR-Institute of Himalayan Bioresource Technology, PO Box No. 6, Palampur 176 061, Himachal Pradesh, India

Full list of author information is available at the end of the article
}

of the compound is reduced for safe clinical use through its transformation into several derivatives. Some of the derivatives such as etoposide (VP-16) and teniposide (VM-26) have anti-cancerous activities and hence podophyllotoxin is in much demand in pharmaceutical industry [2]. Extensive harvesting of the species from nature to meet the requirement of rhizome for podophyllotoxin extraction has led $S$. hexandrum to be listed as endangered species (Appendix II of convention for international trade in endangered species; www.cites.org/eng/app/appendices.php).

Several studies have reported on propagation and conservation of the species [3], podophyllotoxin biosynthesis [4], derivatization of podophyllotoxin, and their mode of action [5]. Also, a few studies have been carried out on plant response to environmental cues. Like other alpine plant species [6], S. hexandrum has been reported to be 
sensitive to high temperature [7]. S. hexandrum consumed more starch at $25^{\circ} \mathrm{C}$ as compared to at $10^{\circ} \mathrm{C}$ leading to poor root growth at the former temperature [7]. Also, the rate of photosynthesis was reported to be lower at $30^{\circ} \mathrm{C}$ as compared to at $20^{\circ} \mathrm{C}$. Higher temperature was also reported to increase the transpiration rate and reduce water use efficiency indicating the species to be sensitive at high temperature [8]. We conducted a preliminary experiment to observe the growth of $S$. hexandrum at four different temperatures. $S$. hexandrum showed partial leaf folding and leaf drooping at $10^{\circ} \mathrm{C}$ and $35^{\circ} \mathrm{C}$, respectively within a span of 3 weeks of temperature exposure, whereas the species did not exhibit such symptoms at $15^{\circ} \mathrm{C}$ and $25^{\circ} \mathrm{C}$; though after 2-3 weeks of temperature, leaves lost shine and developed violet coloured spots at $25^{\circ} \mathrm{C}$ (Additional file 1). The species did not survive for long at $10^{\circ} \mathrm{C}$ and $35^{\circ} \mathrm{C}$.

The objective of the present work was to study the molecular processes at $15^{\circ} \mathrm{C}$ and $25^{\circ} \mathrm{C}$ in commercially important organ rhizome to understand why the species performed better at $15^{\circ} \mathrm{C}$. Transcriptome analysis offers a convenient route to understand molecular processes of the tissue in question. For example, analysis of populus (Populus tremula) transcriptome showed the importance of auxin and gibberellins signaling, and starch metabolism during winters [9]; in sessile oaks [Quercus petraea (Matt.) Liebl.], transcriptome analysis suggested the importance of cell rescue and defense during bud burst after dormancy [10]; subtracted transcriptome analysis in tea [Camellia sinensis (L.) O. Kuntze] identified the significance of genes involved in cell cycle/cell division and stress-inducible genes including those encoding chaperons during winter dormancy [11]. Next generation sequencing has eased transcriptome analysis, and the technology has been successively used to study the transcriptome of several plant species including Himalayan plant species Picrorhiza kurrooa ([12] and the references mentioned therein) to discover genes and markers vis-à-vis to gain insight to important biological and molecular processes. More so, temperature responsive transcriptome of $S$. hexandrum rhizome is not yet reported.

\section{Methods}

\section{Plant material}

Plants of S. hexandrum were collected from Parashar lake, Mandi (2,730 $\mathrm{m}$ above sea level; $30^{\circ} 12^{\prime} \mathrm{N} 77^{\circ} 47^{\prime} \mathrm{E}$, India) and maintained at the institute in Palampur $(1,300 \mathrm{~m}$ altitude; $32^{\circ} 06^{\prime} \mathrm{N}, 76^{\circ} 33^{\prime} \mathrm{E}$, India) for one year in a polyhouse. During the collection procedure, the plants with rhizome of the similar size were selected for various experiments (India's Biological Diversity Act 2002 permits access of biological resources to bonafide Indians for scientific research [13]). Plants from the polyhouse were shifted to two separate plant growth chambers (Percival Scientific, USA) maintained at $15^{\circ} \mathrm{C}$ and $25^{\circ} \mathrm{C}$ with $16 \mathrm{~h}$ photoperiod at a photosynthetic photon flux density of $200 \mu \mathrm{mol} \mathrm{m} \mathrm{m}^{-2} \mathrm{~s}^{-1}$. Plants were irrigated adequately and the rhizome tissue was harvested at day 0 , 14 , and 21 of transfer, cut quickly into smaller pieces using a sharp razor, mixed the cut pieces, frozen in liquid nitrogen and stored at $-80^{\circ} \mathrm{C}$ for further analyses.

\section{Extraction and estimation of podophyllotoxin}

Frozen samples were ground to fine powder in liquid nitrogen using pestle and mortar followed by addition of $700 \mu \mathrm{l}$ of $70 \%$ methanol for $100 \mathrm{mg}$ tissue with intermittent grinding [14-17]. Extract was transferred to a centrifuge tube and the pestle and mortar was rinsed with $300 \mu \mathrm{l}$ of $70 \%$ methanol to recover the left over sample. Extracts were pooled, vortexed for 5 minutes, sonicated (Ultrasonic Cleaner, MC-109-MP, Oscar, India) for 10 minutes at $25^{\circ} \mathrm{C}$ and centrifuged at $14,000 \mathrm{rpm}$ for 5 minutes to collect supernatant for podophyllotoxin estimation. Supernatant was filtered through $0.22 \mu \mathrm{m}$ filter (Millipore, USA) to estimate podophyllotoxin on an Ultra Performance Liquid Chromatography (UPLC) system. The system consisted of Acquity UPLC (Waters, Millford, USA) equipped with binary solvent manager, sample manager, photodiode array detector and a bridged ethyl hybrid workflow shield C18 (1.7 $\mu \mathrm{m}$ particles, $2.1 \times 100 \mathrm{~mm}$ ) analytical column (Waters Corp., Manchester, UK). Mobile phase consisted of methanol and water in a ratio of 60:40. Isocratic elution was carried out at a flow rate of $0.250 \mathrm{ml} \mathrm{min}^{-1}$ with injection volume of $5 \mu \mathrm{l}$. Podophyllotoxin was monitored at $240 \mathrm{~nm}$ and quantified using standard podophyllotoxin (Sigma, USA). Three separate biological replicates were used for each estimation. Significant difference in podophyllotoxin content at $15^{\circ} \mathrm{C}$ and $25^{\circ} \mathrm{C}$ was calculated using Completely Randomized Design to obtain p-value at different sampling times.

\section{RNA extraction, cDNA preparation and transcriptome sequencing}

Various protocols were followed essentially as described previously [12]. In brief, total RNA was extracted from rhizome tissue as described by Muoki et al. [18]. Nanodrop 1000 (NanoDrop Technologies, USA) and a Bioanalyzer Chip RNA 7500 series II (Agilent Technologies, USA) were used to determine quality and quantity of RNA. Oligotex mRNA Midi Kit (Qiagen, Germany) was used to purify mRNA from total RNA, and non-directional Illumina RNA sequencing library was prepared with mRNA-Seq 8 Sample Prep Kit (Illumina, USA) using random primers. Library had an average insert size of $200 \mathrm{bp}$ and eight picomoles of the library [quantified using a Bioanalyzer Chip DNA 12000 series II (Agilent Technologies, USA)] was used for cluster generation. Paired end (PE) $36 \times 2$ bp sequencing was carried out on Illumina Genome Analyzer IIx (Illumina, USA) as per the manufacturer's instructions. 


\section{Expression analysis and validation with quantitative real-time reverse transcriptase mediated polymerase chain reaction (qRT-PCR)}

Total RNA was isolated as described previously [18]. RNA was pretreated with RNase-free DNase I (Invitrogen, USA) and reverse transcribed with $1 \mu \mathrm{g}$ of total RNA using Superscript III (Invitrogen, USA) according to the manufacturer's instructions. Gene specific expression primers for qRT-PCR were designed using GenScript Real-time PCR Primer Design tool [19]. qRT-PCR was performed with three separate biological replicates on a Stratagene Mx3000P System (Agilent Technologies, USA) using $2 \times$ Brilliant II SYBR ${ }^{\circledR}$ Green QPCR Master Mix (Agilent Technologies, USA). PCR was conducted under the following conditions: $10 \mathrm{~min}$ at $95^{\circ} \mathrm{C}$ (enzyme activation), 40 cycles each of $30 \mathrm{~s}$ at $95^{\circ} \mathrm{C}, 30 \mathrm{~s}$ at desired $\mathrm{Tm}$ (Additional file 2 has details), and $72^{\circ} \mathrm{C}$ for 30 s. A final melting curve analysis was performed $\left(55^{\circ} \mathrm{C}\right.$ to $\left.95^{\circ} \mathrm{C}\right)$ to verify specificity of amplicons. Transcript level of all the genes was normalized to an internal reference actin. Expression was estimated using Relative Expression Software Tool [20]. Expression values were transformed $\left(\log _{2}\right)$ to generate expression profiles. All primers used in this study are listed in Additional file 2.

\section{De novo assembly and sequence clustering}

PE sequence reads were generated in FASTq format using CASAVA package GERALD tool provided by Illumina. Our previous publication by Gahlan et al. [12] described strategies and various protocols used for assembly and clustering. $36 \times 2$ bp PE reads were generated for individual sample in each lane. The last three bases from the 3' end of each read were removed to minimize the sequencing error, which is usually higher in the $3^{\prime}$ end of reads. An in-house developed tool, filteR [12], was used to filter out the poor quality reads as well as adapter contaminated reads. De novo assembling of high quality reads was performed using SOAPdenovo tool [21]. A k-mer size of 23 was opted for assembling which yielded high quality PE reads (Additional file 3). PE option of assembling with spacing distance of $200 \mathrm{bp}$ between the PE read was applied to achieve more effective assembling using fragment library size information of PE reads. The same information was also used to build the scaffold sequences by merging two contigs into single scaffold sequence, sharing the read pairs. Figure 1 shows the protocol used in de novo assembling and transcript analysis of assembled sequences for a given sample. Sequence redundancy was removed by searching for similar sequences, keeping minimum similarity cut-off of $95 \%$ for CD-HIT-EST [22]. CD-HIT-EST was used for further clustering with $90 \%$ similarity cutoff. This clustering step was followed by overlap based assembling/clustering, using TGICL-CAP3. It was run with parameters like terminal overlap for at least $40 \mathrm{bp}$ and $90 \%$ identity. The resulting singletons and consensus contigs were merged to get the final list of assembled transcripts. A de-Bruijn graph building approach was used for primary assembling in the initial stage of assembling, which provided long assembled sequences. These long assembled sequences were further taken for redundancy removal and assembling using approaches based on overlap layout consensus and compositional similarity based redundancy crunching. A set of scripts was developed to detect contigs/scaffolds having no sequence similarity but belonged to same gene's different regions. Such sequences were clustered together to represent as a single transcript or unigene. The highest scoring BLASTX hit for all contigs were analyzed for common Non Redundant (NR) ID for a particular gene. All associated contigs showing highest similarity to the same gene but different locations were assigned a single common unigene identification. This approach of Dissimilar Sequence (DS) clustering minimizes the inflated reporting of total unique genes [12].

Information regarding the assembled transcript sequences, associated filtered read data and transcript grouping for unigenes, is available at http://scbb.ihbt.res.in/Podo-12-12-11/. Entire computational analysis was carried out on CentOS Linux based 48 cores $2.2 \mathrm{Ghz}$ AMD processors server with $256 \mathrm{~GB}$ random access memory.

\section{Assembly validation}

To validate assembled transcripts, BLASTN of 1,463 ESTs, downloaded from National Centre for Biotechnology Information (NCBI) dbEST, was performed against transcriptome of $S$. hexandrum using E-value cut-off of $1 \mathrm{e}^{-05}$. Also, selected unigenes involved in podophyllotoxin biosynthesis were validated after DS clustering against complete coding sequences of corresponding genes of $S$. hexandrum submitted in GenBank.

\section{Sequence annotation}

Assembled transcripts of $S$. hexandrum were searched against UniProt database [23], Gene Ontology (GO) [24], Kyoto Encyclopedia of Genes and Genomes (KEGG) [25] and Enzyme Commission number (EC) [26], using BLASTX with a cut-off E-value of $10^{-1}$. Lower cut-off during annotation facilitates annotation even for instances that display only small region matching for some functional domain, which could be missed otherwise with higher cut-off values. Associated GO term was assigned for each assembled transcript by analyzing the GO term for the Uniprot sequence, which returned the highest scoring hit. Similar approach was followed for KEGG and EC classification and annotation for the assembled transcripts. Majority of GO, EC and KEGG based annotations and statistics were done using annotation tool, Annot8r [27] and an in-house developed scripts. Plant Transcription Factor Database (PlnTFDB) [28] 


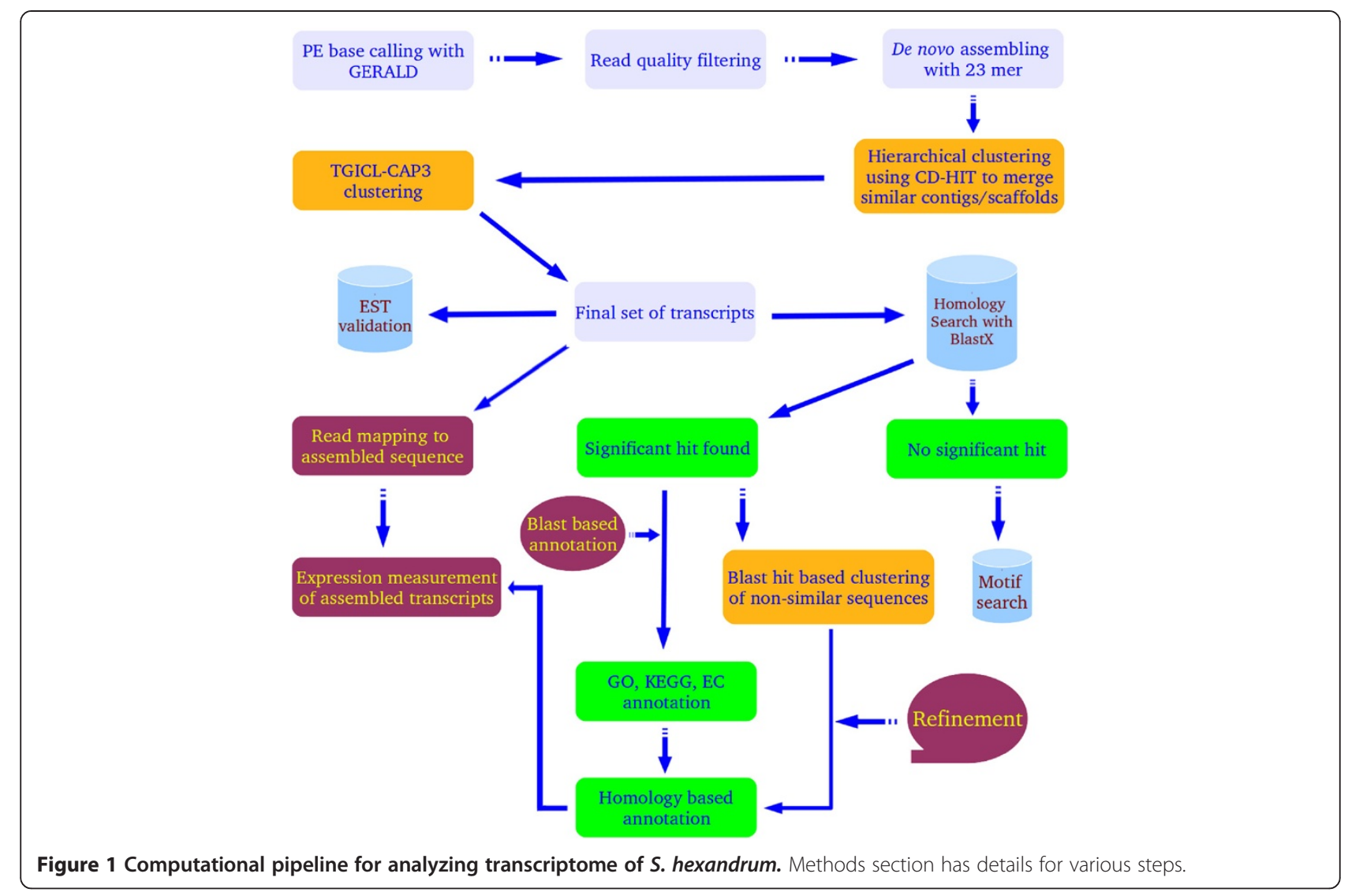

hosts large number of plant specific transcription factors (TFs), their classification, corresponding nucleic acids and protein sequences. Data for all TFs reported in PlnTFDB, version 3.0, were downloaded for the current study. The assembled transcript sequences were searched against this database using BLASTX with an E-value threshold of $10^{-5}$. Top scoring homologous sequences from PlnTFDBs were used to annotate the assembled transcripts displaying highest similarity.

$S$. hexandrum transcript sequences were searched against MIPS Functional Catalogue (FunCat) [29] database to classify transcripts based on functional categories classified at MIPS. FunCat hierarchy is based on the Arabidopsis thaliana transcriptome. Therefore, BLASTX search was performed against the Arabidopsis transcriptome (downloaded from TAIR 10 [30]). The IDs from top scoring Arabidopsis gene hits were extracted and mapped to the $S$. hexandrum transcript sequences to categorize them into various FunCat categories.

\section{Functional domain search for unknown sequences}

The assembled sequences which did not return any homologous sequence hit during BLASTX search were converted into six longest ORFs. These ORFs were scanned against the functional domain databases like
Conserved Domain Database (CDD) [31], using RPSBLAST UNIX version.

\section{Read mapping and transcript expression abundance measurement}

Since a reference genome was not available in the present study, the filtered reads were mapped to the assembled transcripts. This was followed by estimation of total mapped reads. Uniquely mapped reads assigned to each assembled transcript with maximum two mismatches were allowed. Read mapping was done using TopHat which uses Bowtie to map the reads on transcripts [32] while differential abundance in terms of FPKM was measured using Cuffdiff [33] which deploys t-test and Benjamini-Hochberg correction to compute significance difference between samples and adjusts the p-value after false discovery rate for multiple hypothesis testing. Using the reads from $15^{\circ} \mathrm{C}$ and $25^{\circ} \mathrm{C}$ experiments, the relative abundance of transcripts was estimated for each unigene for the two temperatures for the sequence clusters generated following the DS clustering [12]. DS clustering reduced the inflation of unique genes representation and mapped that information on every part of the study. The read data obtained for the two temperatures were mapped on the assembled transcripts separately. Care was taken to ensure that only those lanes and reads 
were considered for both the temperatures which had equal sample concentration and produced almost equal percentage of reads qualifying the filtering cut-off, ensuring that experimental conditions do not skew the read representation and analysis.

The associated GO terms (GO terms are derived from dynamic controlled vocabularies or ontologies that can be used to describe the function of genes and gene products) and IDs were mapped to each of these unique transcripts and genes, providing single stop complete information regarding their related expressions at the two temperatures and their corresponding annotations.

\section{Guanine-cytosine (GC) content analysis and simple sequence repeats (SSRs) identification}

GC content of the sequences was measured using Emboss GeeCee tool, while sequences were scanned for SSR markers using MISA [34].

\section{Metabolic networks and pathways analysis}

Sequences were scanned against KEGG using BLAST. FPKM was considered for all the assembled sequences. Plant Metabolic Network (PMN) database [35] was searched for all the significantly up-regulated genes using an in-house developed network running script. Using the same script, pathways network images were generated and corresponding transcript, expression and other associated information were incorporated into the files.

\section{Results and discussion}

Rhizome biology for $S$. hexandrum is of interest not only that rhizome is the source of medicinally important compound podophyllotoxin, but also it allows plant to survive the unfavorable environment of winters when aerial portion of the plant dies. Plant regenerates from the rhizome upon arrival of the growing season. Availability of vast genomic and transcriptomic data in the public domain coupled with next generation sequencing platforms made it possible to understand temperature responsive biology of rhizome of $S$. hexandrum. Since plants appeared healthier at $15^{\circ} \mathrm{C}$ as compared to at $25^{\circ} \mathrm{C}$ (Additional file 1), the present work analyzed transcriptome in the rhizome tissue at the two temperatures vis-à-vis podophyllotoxin content.

\section{Podophyllotoxin accumulation at two temperatures}

Several studies showed modulation of secondary metabolism in response to external cues [36,37]. In the present work podophyllotoxin content did exhibit a decreasing trend of accumulation, from day 14 and onwards of the exposure of plants to $25^{\circ} \mathrm{C}$ as compared to those at $15^{\circ} \mathrm{C}$ (p-values for day 14 and 21 were 0.393 and 0.686 , respectively; F values for day 14 and 21 were 1.196 and 0.393 , respectively) (Figure 2). Though there is no report on the effect of temperature on podophyllotoxin accumulation,

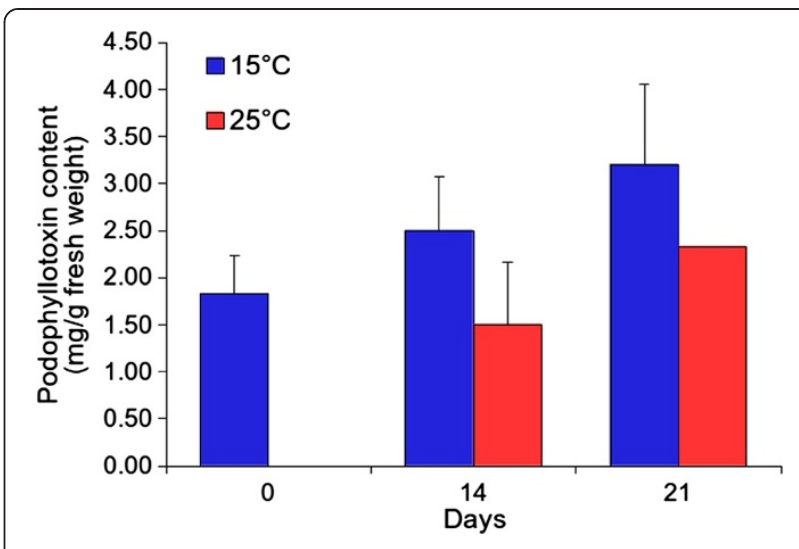

Figure 2 Effect of temperature on accumulation of podophyllotoxin content in rhizome tissue of S. hexandrum. Rhizome tissue was harvested at day 0, 14 and 21 from plants kept at $15^{\circ} \mathrm{C}$ and $25^{\circ} \mathrm{C}$ to measure podophyllotoxin content. Difference in the podophyllotoxin content at two temperatures was statistically insignificant as analyzed by Completely Randomized Design (CRD); though a decreasing trend of accumulation was observed at $25^{\circ} \mathrm{C}$. Each value is a mean of three separate biological replicates. Error bars are standard error of the mean of three biological replicates.

one group [38] did report decreased accumulation of podophyllotoxin content at low $(1,500 \mathrm{~m})$ as compared to at high altitude $(3,000 \mathrm{~m})$ [38], where temperature is one of the major cues which is higher at lower altitude [39]. A decreasing trend of podophyllotoxin accumulation at higher temperature did suggest modulation of rhizome biology of $S$. hexandrum by temperature.

\section{Reads generation and de novo sequence assembly}

A total of $146,304,154 \mathrm{PE}$ reads were obtained at $15^{\circ} \mathrm{C}$ while a total of 54,176,602 $\mathrm{PE}$ reads were obtained at $25^{\circ} \mathrm{C}$. By deploying a read filtering tool, FilteR [12], a total of $125,957,408$ and $44,346,624$ high quality $\mathrm{PE}$ reads were obtained for $15^{\circ} \mathrm{C}$ and $25^{\circ} \mathrm{C}$, respectively (total 170,304,032 PE reads). Selection of appropriate $\mathrm{k}$-mer size is an important step in de novo assembly, since it varies for species and data type. SOAPdenovo was run to assemble transcripts of $S$. hexandrum from high quality reads at different k-mer size ranging from 19 to 29 . K-mer size of 23 mer was chosen for de novo assembly as it displayed a balance between over- and under-represented transcript numbers, coverage of reads on transcripts, maximum length of transcript, percentage of transcripts having length higher than 1,000 bp and average transcript length (Additional file 3). Number of transcripts decreased linearly with increasing $\mathrm{k}$-mer size suggesting under-representation at high k-mers and over-representation at lower k-mer length. Similarly, at high k-mer higher coverage or higher expression was observed for the assembled sequences. These steps were taken for evaluating the quality of assembled transcripts. Gap filling produced longer scaffolds from the 
PE reads data which mapped into the contigs as well as gapped regions. Collective assembly of the filtered reads yielded a total of 60,089 transcripts, $15.57 \%$ of which were above $1 \mathrm{~kb}$, with a coverage of $88.34 \mathrm{X}$, average length of $543.11 \mathrm{bp}$ and maximum length of $14,390 \mathrm{bp}$ (Table 1 ).

\section{Homology search, sequence clustering, validation of} assembled transcripts and general traits of the transcriptome The number of unique assembled transcripts reduced from 60,089 to 59,244 sequences after removing the redundancies. These were clustered together under a common Unigene group, and BLASTX [40] with cut-off E-value of $10^{-5}$ showed that a total 25,395 sequences had significant BLAST hit. Remaining 33,849 sequences without significant BLAST hit did show conserved domains in 761 sequences (Additional file 4), suggesting a possible function for these unknown sequences. DS clustering [12] further reduced the total sequences from 25,395 to 20,387 (Additional file 5; URL: http://scbb.ihbt.res.in/Podo-12-12-11/).

A total of 1,463 ESTs of $S$. hexandrum were reported in NCBI dbEST, out of which BLAST hits were found for 975 ESTs (66.64\%) when searched against the transcriptome. These ESTs showed an average identity of $\sim 93.50 \%$ indicating good quality of assembled transcripts. Of the total, $19.69 \%$ of ESTs (192/975) had coverage greater than 90\% whereas $52.82 \%$ ESTs (515/975) showed coverage of $50 \%$ or more. To evaluate correct assembly of unigenes, coding sequences of five selected genes (accession numbers GU324975.1, EU240218.2, GU196273.1, KF170372.1 and GU228507.1) involved in podophyllotoxin biosynthesis pathway were searched against unigenes using BLASTN. Analysis yielded average coverage of $95.05 \%$ (Additional file 6), suggesting that the unigenes were correctly assembled.

Average GC content of $S$. hexandrum transcripts was found to be around $44.59 \%$ out of which $80 \%$ of transcripts had the content in the range of 40-49\%, a range comparable to that reported for dicots (44-47\%) [41] (Additional file 7). GC content of genome indicates several features including genome stability and possible repeats dynamics [42]. Assembled transcript sequences of $S$. hexandrum identified a total of 3,226 SSRs. Most abundant SSR group was of tri-nucleotide (54.40\%) with GAA, TTC, TCT, CAC and CCA as predominant repeats, followed by di-nucleotide $(36.38 \%)$ with prevalent occurrence of
poly-CT (261), and mono-nucleotide (19.36\%) SSRs represented by Poly-T (272) as a dominant repeat. Only a small fraction of tetra (32) and hexa (3) SSRs contributed to the pool (Additional file 7). SSRs are used in production and control of strains as well as dissemination of important genes apart from being the source of polymorphism and marker of genome [43].

\section{Functional annotation and classification of the \\ S. hexandrum transcriptome}

Annotation of 20,387 assembled sequences against GO database yielded significant annotation for 15,810 unique transcripts that were classified into biological processes, molecular functions and cellular component using plant specific GO slims. Functional classification in biological process category (Additional file 8) revealed that metabolic process, response to stimulus, cellular process and multicellular organismal development were among the highly represented groups, suggesting tissue to be metabolically active. Genes involved in DNA binding, catalytic and transferase activity were highly represented in molecular function category (Additional file 8), indicating dominance of gene regulation, signal transduction and enzymatically active processes. Among the cellular components (Additional file 8), genes for intracellular location and those encoding for membrane localized protein were most represented, which is a typical character of a eukaryotic cell.

Best EC classification was obtained for 8,172 assembled sequences after DS clustering. An analysis of top 50 abundant enzyme classes showed predominance of serine/threonine protein kinase enzyme (21.73\%; Additional file 9A), which is known to be involved in regulation of cell proliferation, programmed cell death (apoptosis) and cell differentiation [44]. Associated KEGG classification could be obtained for 8,759 assembled sequences. An analysis of top 50 KEGG pathways showed that plant hormone signal transduction pathways (5.74\%) dominated the group (Additional file 9B), followed by plant-pathogen interaction. GO, EC and KEGG analysis showed rhizome to be a metabolically active tissue.

\section{Global analysis of transcript abundance in response to temperature}

Read mapping-based method of estimation of transcript abundance offers high throughput gene expression data,

Table 1 Summary of transcriptome data generated on Illumina Genome Analyzer Ilx for rhizome tissue of S. hexandrum

\begin{tabular}{|c|c|c|c|}
\hline & $15^{\circ} \mathrm{C}$ & $25^{\circ} \mathrm{C}$ & Total \\
\hline Total number of paired end reads & $146,304,154$ & $54,176,602$ & $200,480,756$ \\
\hline Number of reads obtained after quality filtering & $125,957,408$ & $44,346,624$ & $170,304,032$ \\
\hline Number of primary assembled transcripts of pooled data & Not applicable & Not applicable & 60,089 \\
\hline Average length of transcripts $(b p)$ of pooled data & Not applicable & Not applicable & 543.11 \\
\hline Average coverage $(X)$ of pooled data & Not applicable & Not applicable & 88.34 \\
\hline
\end{tabular}


especially for those organism whose genome/transcriptome is not sequenced $[12,45]$. GO annotation was obtained for 15,708 unique genes along with their FPKM values at the two different temperatures. Distribution of $S$. hexandrum unigenes across various molecular function categories (Figure 3) revealed prominent up-regulation of several genes including for protein kinase activity, and calcium ion binding at $15^{\circ} \mathrm{C}$. While genes associated with monoxygenase activity, peptidase activity, galactinol-sucrose galactosyltransferase activity were over-expressed at $25^{\circ} \mathrm{C}$. Of the various biological process categories (Figure 4), hydrogen peroxide catabolic process, and response to biotic stimulus were prominent at $15^{\circ} \mathrm{C}$, whereas response to stress, and auxin mediated signaling pathway exhibited significant over expression at $25^{\circ} \mathrm{C}$.

KEGG identified pathways for 8,711 representative sequences, which were mapped for abundance and analyzed for their behavior at the two temperatures. Some of the pathways that exhibited significant over-expression at $15^{\circ} \mathrm{C}$ included those associated with citrate cycle and metabolism of ascorbate, sucrose and glutathione (Figure 5). Glutathione has been shown to have implications in heat, drought and cold responses [46]. An interesting feature was over-expression of phenylpropanoid (PP) biosynthesis pathway at $15^{\circ} \mathrm{C}$, the pathway that supplies precursor for podophyllotoxin biosynthesis.

FunCat analysis (Figure 6; Additional file 10) revealed up-regulation at $25^{\circ} \mathrm{C}$ of genes involved in cell rescue, cell fate, cell cycle and DNA processing, apart from other genes. GO and FunCat analysis revealed that the genes associated with growth and development were over-expressed at $15^{\circ} \mathrm{C}$. Whereas, genes involved in stress response, cell rescue and cell fate were expressed at $25^{\circ} \mathrm{C}$.
PMN analysis using homologous genes exhibiting 2-fold or higher expression at $15^{\circ} \mathrm{C}$ is mentioned at http://scbb.ihbt.res.in/Podo-12-12-11/podo_pathway_go/ Genes_at_15_degree_having_expression_2_fold_or_above/. Every network diagram contains the pathway information, associated homologous gene, transcript ID, and expression/ abundance in terms of FPKM; each file name contains the associated transcript's scaffold/contig ID in its prefix to make the browsing job easier. The file "podophyllum_analysis.doc" in the parent directory of the above link contains tabular representation and details about all such assembled transcripts, associated homologue reported in PMN, associated gene and associated PMN metabolic pathway/network.

Data showed up-regulation of pathways for respiration, photosynthesis, and phenylpropanoid biosynthesis at $15^{\circ} \mathrm{C}$. These are fundamental pathways that would be crucial for growth and survival of plants at $15^{\circ} \mathrm{C}$. Data showed up-regulation of ABA biosynthesis, ethylene and jasmonic acid, and is suggestive of their roles in plant growth and development at $15^{\circ} \mathrm{C}$ through functioning as signal molecule [47]. Up-regulation of phenylalanine metabolism, fatty acid biosynthesis, starch and sucrose metabolism and PP pathway at low temperature is also reported in cassava (Manihot esculenta) transcriptome [48]. This global analysis of gene expression provided a comprehensive data-set with each gene represented by its absolute expression level at two temperatures.

\section{Validation of FPKM-based analysis by quantitative} real-time polymerase chain reaction (qRT-PCR)

FPKM based expression values were validated by qRT-PCR using sixteen genes related to growth and development

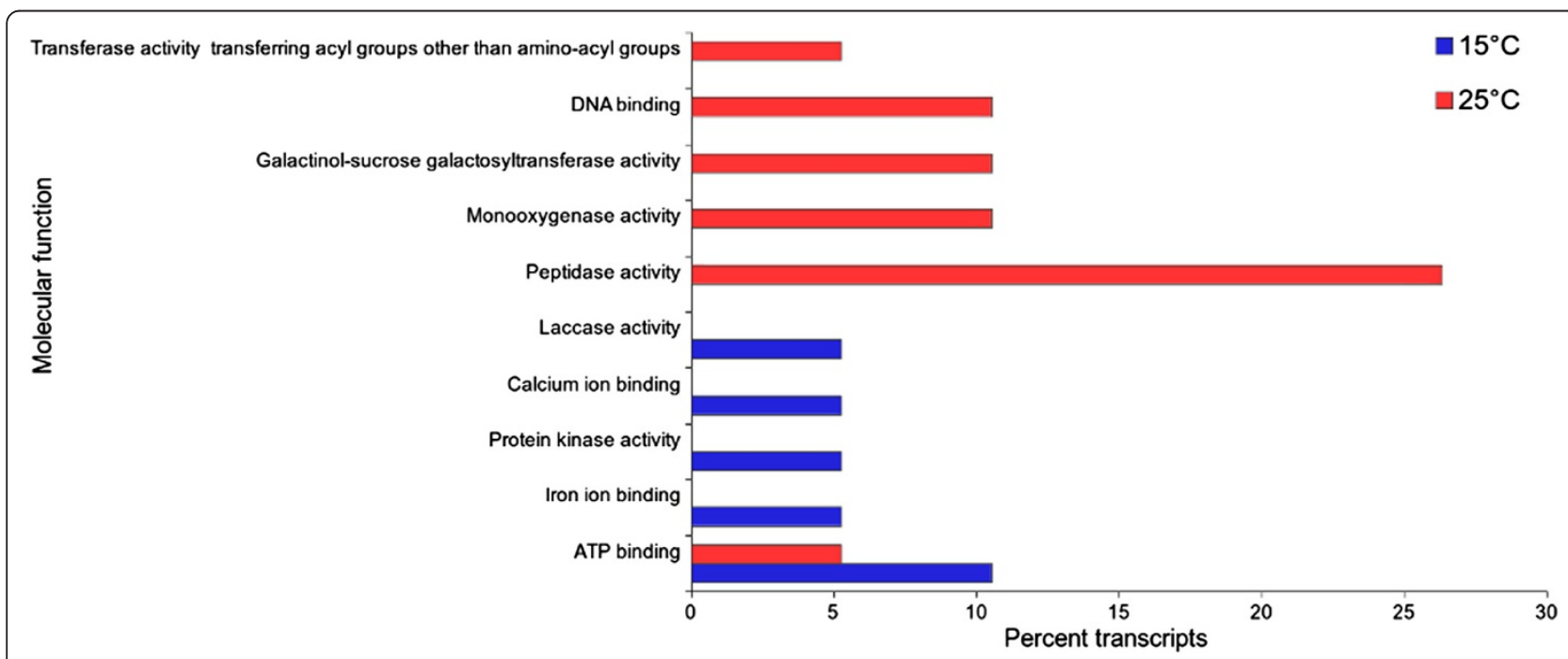

Figure 3 Percent transcripts in transcriptome characterized for molecular function category which exhibit significant over-expression at $15^{\circ} \mathrm{C}$ and $25^{\circ} \mathrm{C}$ as compared to those at $25^{\circ} \mathrm{C}$ and $15^{\circ} \mathrm{C}$, respectively. 


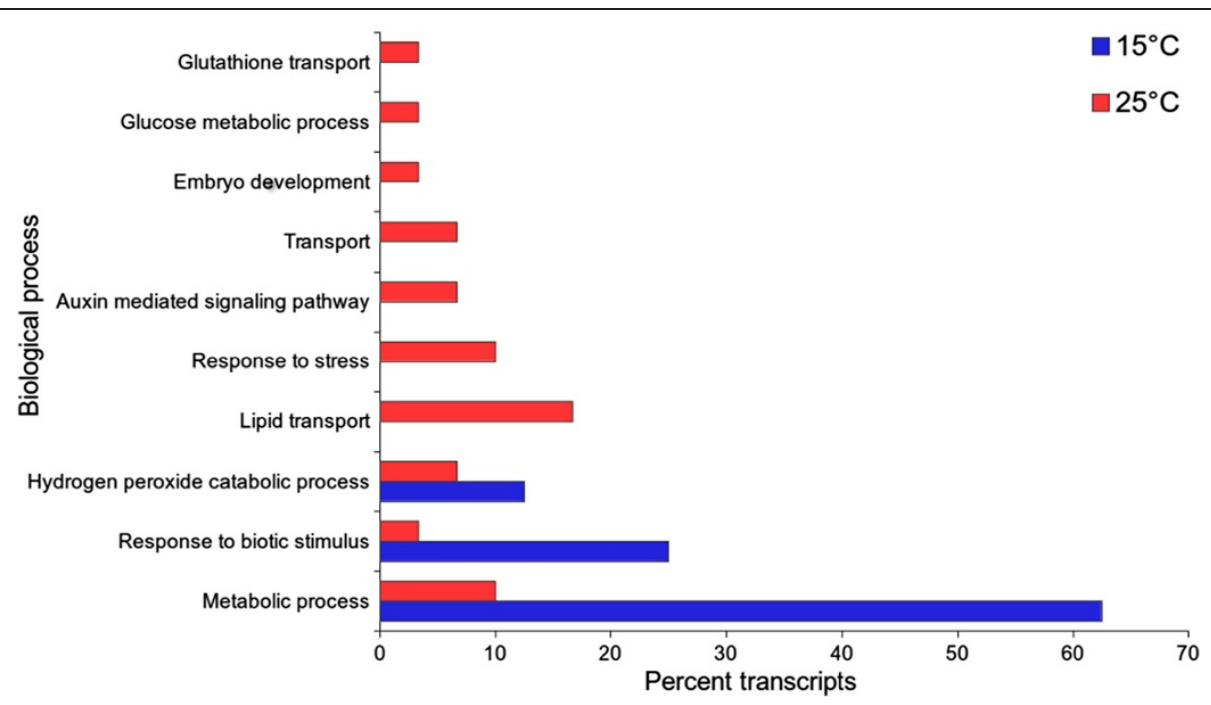

Figure 4 Percent transcripts in transcriptome characterized for biological process category which exhibit significant over-expression at $15^{\circ} \mathrm{C}$ and $25^{\circ} \mathrm{C}$ as compared to those at $25^{\circ} \mathrm{C}$ and $15^{\circ} \mathrm{C}$, respectively.

and stress response. These genes were NEDD8, CTPS, $A T H B-14, A B T B 2, A P 2, C O, C S L A, C P N 60, Z F P, A O X 1 a$, STK, HSP60, HSP, AP2D, FRO and TINY. Cullin-associated NEDD8-dissociated protein 1 regulates cell division, stress responses and hormonal signaling [49]. CTP synthase is involved in embryo development [50]. Homeobox-leucine zipper protein ATHB-14 (HDZip) family of TFs acts in developmental processes and in the mediation of external signals to regulate plant growth [51]. ABTB2, AP2 and $C O$ were reported to play a role in morphogenesis in Arabidopsis [52-54]. CSLA is required for synthesis of cell wall polysaccharide mannan which serves as storage reserve during plant growth and development [55]. CPN60 was essential for development of embryo and seedling [56].

ZFP plays an important role in stress signaling in Arabidopsis [57]. AOX1a was reported to prevent formation of excessive reactive oxygen species under stress condition [58]. STK is expressed in response to biotic and abiotic stress [59]. HSP60 and HSPs encode proteins that prevent damage to cellular protein in response to heat stress [60]. $A P 2 D$ is involved in abiotic stress [61]. FRO is required for iron transport across membranes for efficient photosynthesis [62]. TINY is associated with both abiotic and biotic stress signalling pathway and its over-expression suppressed cell proliferation [63]. FPKM and qRT-PCR based expression data were in accordance with each other with a correlation coefficient of $0.811\left(\mathrm{p}\right.$-value $\left.=7.86 \mathrm{e}^{-05}\right)$ (Figure 7; Additional file 2). These values are considered significant $[64,65]$ and offer confidence to use FPKM based expression values to represent change in gene expression.

\section{Transcription factor and expression enrichment}

TFs are sequence specific DNA-binding proteins that interact with the promoter regions of target genes and modulate gene expression. These proteins regulate gene transcription depending upon tissue type and in response to internal signals, for example, plant hormones, and to external signals such as temperature, UV light, pathogen attack and drought. Coordinated transcriptional control of genes is one of the major mechanisms regulating various processes [12]. In $S$. hexandrum 16,473 transcript sequences exhibited homology with TF families, which was reduced to 7,853 after DS clustering. The most abundant TF families observed were those encoding for $\mathrm{C} 3 \mathrm{H}$, bHLH, PHD, C2H2, AP2-EREBP and MYB (Additional file 11). Of the $7,853 \mathrm{TFs}, 0.44 \%$ were found to be significantly over expressed at $15^{\circ} \mathrm{C}$ (Additional file 12). The most abundant TFS in this group were WRKY, HB, SET, Orphans, MYB, GRAS and $b H L H$. A total of $0.41 \%$ TFs exhibited significant abundance increment at $25^{\circ} \mathrm{C}$, and these were $\mathrm{C} 3 \mathrm{H}, \mathrm{C} 2 \mathrm{H} 2$, $b Z I P$ and AP2-EREBP. These TFs have been reported to play a role in stress response. The median fold expression was found higher for several TF families at $15^{\circ} \mathrm{C}$ (Table 2). TF bHLH is regulatory component involved in many developmental pathways as well as in plants metabolism [66]. MYB is implicated in response to development and metabolism [67]. TF PHD is a transcriptional regulator [68], and NAC regulates cell division and senescence [69]. $\mathrm{C} 2 \mathrm{H} 2$ is associated with RNA metabolism and chromatin remodeling [70]. TF data showed operation of various cascades associated with growth and development at low temperature, while stress-responsive TFs were operative at high temperature (Table 2).

Thus, transcriptome analysis including TF, GO, FunCat, $\mathrm{EC}$ and PMN data (Figures 3, 4, 5 and 6) suggested that $15^{\circ} \mathrm{C}$ favored growth and development, whereas $25^{\circ} \mathrm{C}$ imposed stress on S. hexandrum; and also supported the observation of better growth of plant at $15^{\circ} \mathrm{C}$ (Additional file 1). 


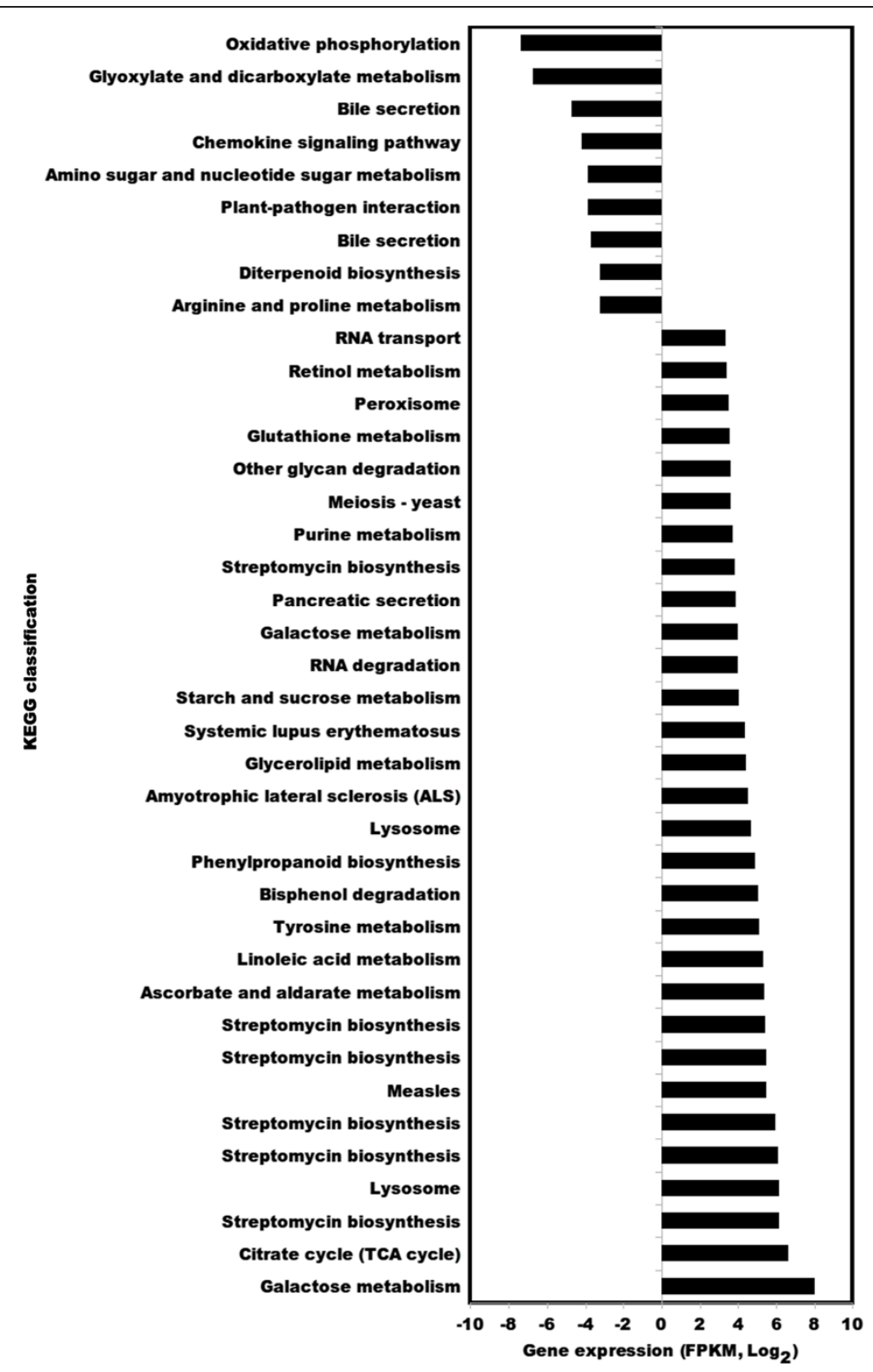

Figure 5 Top 50 Kyoto Encyclopedia of Genes and Genomes (KEGG) pathways of significantly over- and under-expressed transcripts at $15^{\circ} \mathrm{C}$ as compared to at $25^{\circ} \mathrm{C}$.

Expression of genes involved in podophyllotoxin biosynthesis at the two temperatures

Transcriptome data was used to identify various genes involved in the biosynthesis of podophyllotoxin, a lignan moiety. Glucose-6-phosphate is the central precursor for synthesis of a range of compounds in a living cell. The molecule produces phosphoenolpyruvate through glycolysis and erythrose-4-phosphate by oxidative pentose phosphate pathway. These two molecules synthesize chorismate through shikimate pathway. Chorismate synthesizes three aromatic amino acids tryptophan, phenylalanine and tyrosine out of which phenylalanine enters the PP pathway to synthesize $p$-coumaroyl-CoA (Figure 8). Bioconversion studies of radioactive precursors suggested coniferyl alcohol, a monolignol, to be the key precursor in the biosynthesis of podophyllotoxin [71]. Synthesis of coniferyl alcohol is achieved through several reactions starting from $p$-coumaroyl-CoA. One of the first enzymes in the sequence is $p$-hydroxycinnamoyl-CoA: quinate shikimate p-hydroxycinnamoyl transferase (HCT), which is known to catalyze two different steps. HCT catalyzes transfer of the $p$-coumaroyl group to shikimate [72] leading to formation of $p$-coumaroyl shikimate which in turn is hydroxylated by $p$-coumarate 3 -hydroxylase $(\mathrm{C} 3 \mathrm{H})$ to 


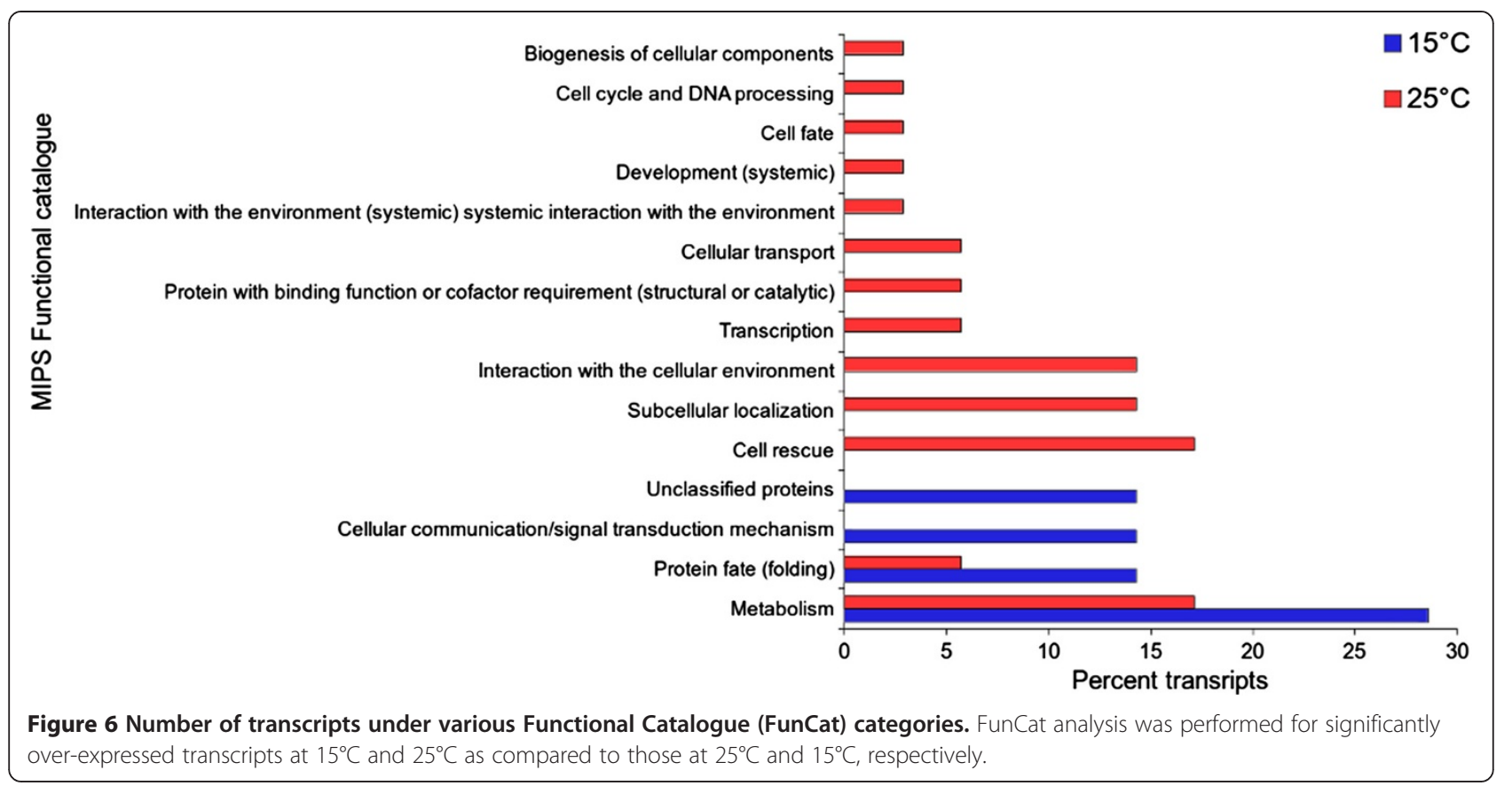

produce caffeoyl shikimate [73]. Following the formation of caffeoyl shikimate, HCT also catalyzes transfer of caffeoyl moiety back to Coenzyme A yielding caffeoyl-CoA. Caffeoyl-CoA O-methyltransferase (CCoAOMT) methylates caffeoyl-CoA and synthesizes feruloyl-CoA followed by its reduction to synthesize coniferaldehyde by involving the action of cinnamoyl-CoA reductase (CCR). Last step in biosynthesis of lignin monomer is catalyzed by cinnamyl alcohol dehydrogenase (CAD), which catalyzes
NADPH-dependent reduction of coniferaldehyde to coniferyl alcohol [74].

Studies on biosynthetic pathway of podophyllotoxin in Podophyllum peltatum and Linum flavum established occurrence of dirigent protein mediated coupling of coniferyl alcohol to get pinoresinol by involving the action of dirigent protein oxidase (DPO) [75]. Sequential conversion of pinoresinol to lariciresinol and secoisolariciresinol by the action of pinoresinol-lariciresinol

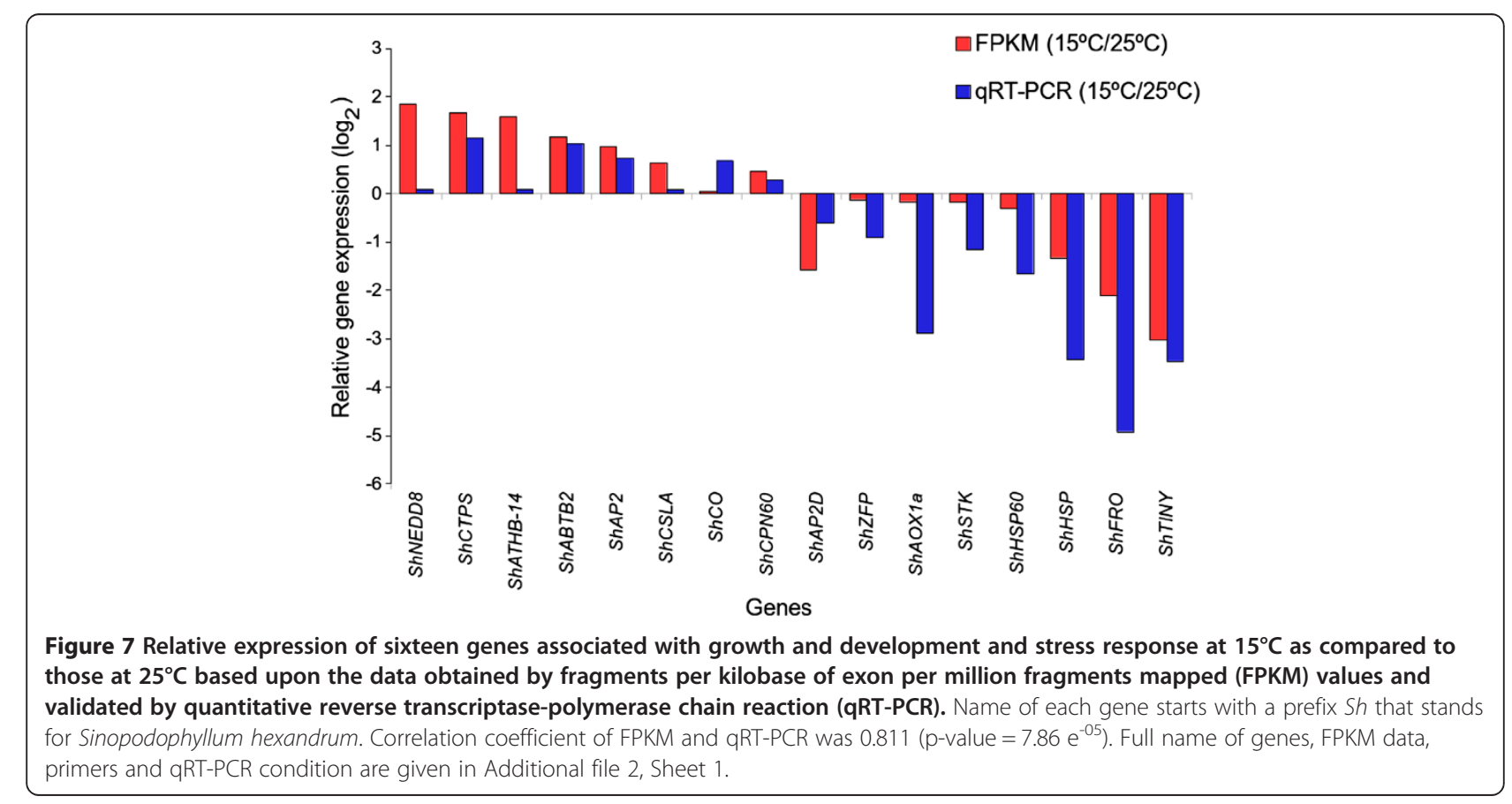


Table 2 Transcription factor families exhibiting significant difference in expression (based upon FPKM values) at $15^{\circ} \mathrm{C}$ and $25^{\circ} \mathrm{C}$ in rhizome of S. hexandrum

\begin{tabular}{|c|c|c|}
\hline TF Name & $\begin{array}{l}\text { Median fold enrichment } \\
{\left[15^{\circ} \mathrm{C} / 25^{\circ} \mathrm{C}\right]}\end{array}$ & $\begin{array}{c}\text { Median fold enrichment } \\
{\left[25^{\circ} \mathrm{C} / 15^{\circ} \mathrm{C}\right]}\end{array}$ \\
\hline$A B \mid 3 V P 1$ & 11.8496004672 & 0.084391031 \\
\hline$A P 2-E R E B P$ & 0.0993436445 & 10.0700936999 \\
\hline$A R F$ & 251.2693584621 & 0.0039797929 \\
\hline$B B R / B P C$ & 0.0222768823 & 44.8895849311 \\
\hline bHLH & 34.9929358021 & 0.0285771964 \\
\hline$b Z I P$ & 0.0168311473 & 59.6713654895 \\
\hline $\mathrm{C} 2 \mathrm{H} 2$ & 0.0608432609 & 19.5386817714 \\
\hline $\mathrm{C} 3 \mathrm{H}$ & 0.0503718206 & 19.8523695815 \\
\hline CCAAT & 0.0840696948 & 11.8948927191 \\
\hline$C S D$ & 0.0625543682 & 15.9860938481 \\
\hline FAR1 & 0.0644243725 & 15.5220759063 \\
\hline$F H A$ & 0.0438438485 & 22.8082167472 \\
\hline G2-like & 83.8294374002 & 0.0119289838 \\
\hline GRAS & 56.8761946615 & 0.0178378292 \\
\hline$H B$ & 24.9465837862 & 0.0409371239 \\
\hline$H M G$ & 271.7954207871 & 0.0036792379 \\
\hline Jumonji & 6.002434472 & 13.3464369086 \\
\hline$\angle O B$ & 33.1564538771 & 0.0301600407 \\
\hline MADS & 13.3186291414 & 0.0750828024 \\
\hline MYB & 18.2000355303 & 0.0549449477 \\
\hline MYB-related & 17.0809876818 & 0.0585446239 \\
\hline$N A C$ & 0.1193331901 & 8.3798983242 \\
\hline Orphans & 45.9958631506 & 8.7044704786 \\
\hline PHD & 0.0087271093 & 114.6268134388 \\
\hline SET & 41.296776066 & 0.0341751871 \\
\hline SNF2 & 8.4420467469 & 26.9126761966 \\
\hline SRS & 12.9995925944 & 0.0769254877 \\
\hline Trihelix & 27.1957822459 & 0.0367704077 \\
\hline VARL & 250.1042595646 & 0.0039983325 \\
\hline WRKY & 17.1515127277 & 0.0583038952 \\
\hline
\end{tabular}

reductase (PLR) was revealed by radiolabeled substrate study [76,77]. Secoisolariciresinol is dehydrogenated to matairesinol by action of secoisolariciresinol dehydrogenase (SLD) [78]. The enzymatic reactions between matairesinol to deoxypodophyllotoxin are not well characterized. A direct pathway from matairesinol to yatein is proposed by tracer experiments in Anthriscus sylvestris [79] and pathway from yatein to podophyllotoxin via deoxypodophyllotoxin was suggested by feeding experiment [80], but not yet deciphered. Deoxypodophyllotoxin is considered as the precursor for biosynthesis of podophyllotoxin [81] as supported by feeding experiment in
S. hexandrum [82] and Linum flavum [83,84]. Hydroxylation of deoxypodophyllotoxin by deoxypodophyllotoxin 7-hydroxylase $(\mathrm{DOP} 7 \mathrm{H})$ involved in the biosynthesis of podophyllotoxin is yet to be characterized [85] (Figure 8).

Starting from phenylalanine, there are twelve known genes involved in the biosynthesis of podophyllotoxin (Figure 8). Transcriptome data identified all these twelve genes. FPKM showed up-regulation of eight genes namely, phenylalanine ammonia lyase (ShPAL), 4-coumarate: CoA ligase (Sh4CL), caffeic acid 3-O-methyltransferase (ShCOMT), ShCCR, ShPLR, ShSLD, ShCAD and dirigent protein oxidase $(S h D P O)$ at $15^{\circ} \mathrm{C}$ as compared to at $25^{\circ} \mathrm{C}$. Whereas, expression of $\mathrm{ShC} 4 \mathrm{H}$, ShHCT, $\mathrm{ShC} 3 \mathrm{H}$ and ShCCoAOMT showed down-regulation at $15^{\circ} \mathrm{C}$. Validation of gene expression by qRT-PCR showed similar trend of gene expression as obtained by FPKM, with correlation coefficient of 0.740 ( $p$-value $=0.009$ ) between the two platforms for gene expression (Figure 9). Interestingly, the trend of podophyllotoxin content accumulation was higher at $15^{\circ} \mathrm{C}$ as compared to those at $25^{\circ} \mathrm{C}$ (Figure 2). Thus the results were in accordance with previous reports where gene expression and the metabolite concentration were positively correlated with each other. For example, catechins content in Camellia sinensis was positively correlated with the expression of genes of its biosynthetic pathway [86] and similar were the conclusions for picrosides content in P. kurrooa [87], steviosides content in Stevia rebaudiana [88] and shikonins content in Arnebia euchroma [89].

Transcriptome data identified cytochrome P450 (CYPs), methyltransferases (MTs) and UDP-glycosyltransferases (UGTs), possibly associated with the biosynthesis of podophyllotoxin

CYPs are membrane bound heme proteins, which catalyze hydroxylation, epioxidation, dealkylation and oxidation reactions. CYPs constitute the third known largest family of plant genes involved in numerous biosynthetic reactions resulting in production of plant hormones, defensive compounds, and secondary metabolites [90]. In podophyllotoxin biosynthetic pathway, hydroxylation at position 7 of deoxypodophyllotoxin by deoxypodophyllotoxin 7-hydroxylase (DOP7H) leads to the synthesis of podophyllotoxin, but the enzyme and the gene are yet to be characterized [82,91]. Therefore, detailed analysis of CYPs was important.

Transcriptome data identified 116 CYPs based on highest bit score and significant E-value. CYP-39 (scaffold11394_153.2) was found to be significantly up-regulated at $25^{\circ} \mathrm{C}$ by cuffdiff (Additional file 13). Fifteen CYPS showed more than two fold up-regulation, while 24 showed down-regulation at $15^{\circ} \mathrm{C}$ as compared to at $25^{\circ} \mathrm{C}$ (Additional file 14). These 39 CYPs could be the potential candidates for detailed analysis to identify the putative ShDOP7H. 


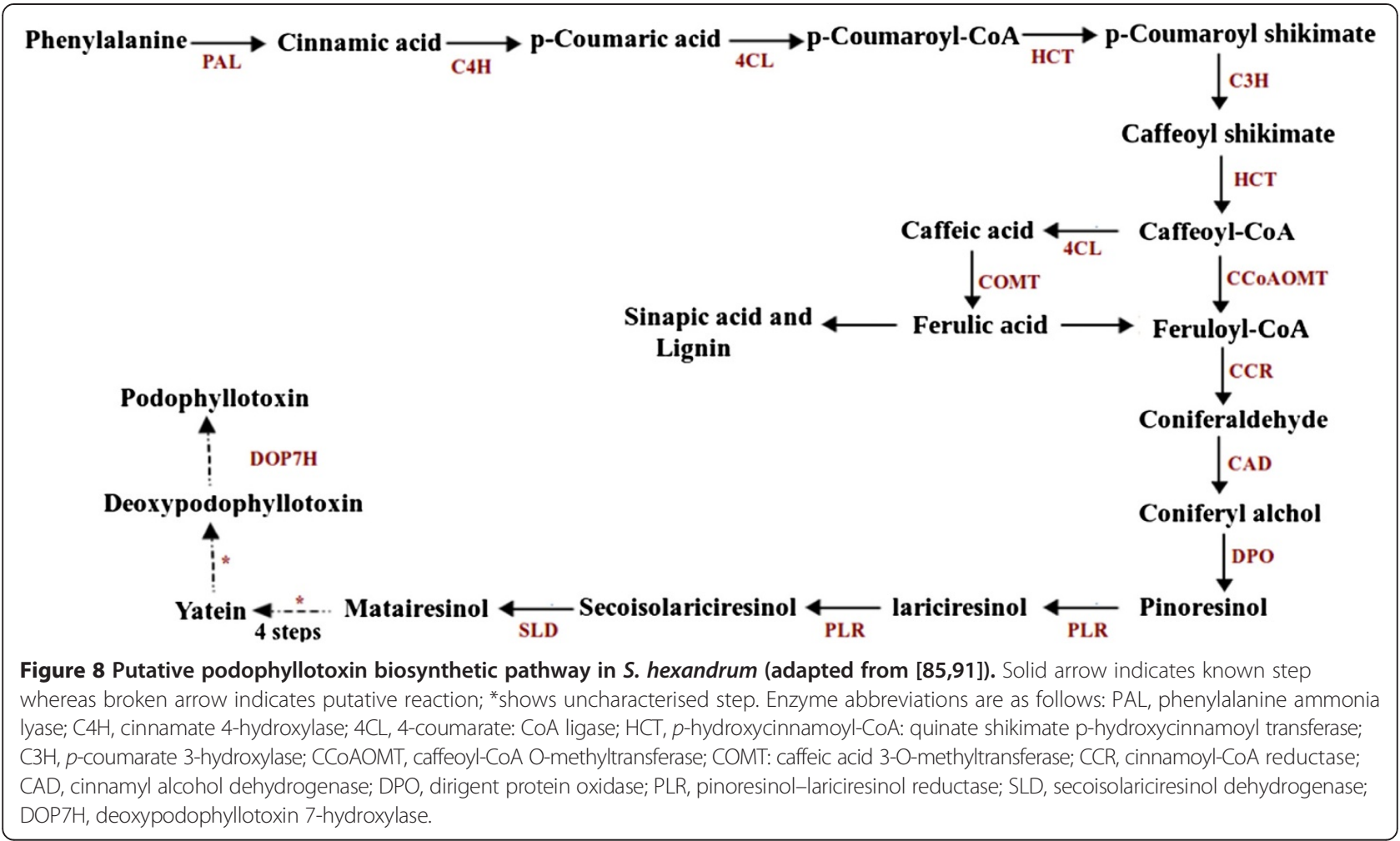

MTs are transferase enzymes that participate in transfer of a methyl group from a donor to an acceptor. O-methylation plays important role in biosynthesis of lignan including podophyllotoxin [92]. Ferulic acid and sinapic acid are methylated compounds and are precursor of monolignols (coniferyl and sinapyl alcohols), the moieties involved in lignin biosynthesis [93]. MTs are essential in PP pathway: activity of CCoAOMT is essential for coniferyl and sinapyl alcohols biosynthesis [94]; and COMT is the key enzyme involved in methylation using hydroxycinnamates as substrates [95]. Tracer studies in Anthriscus sylvestris revealed that conversion of matairesinol to yatein involves four steps that include hydroxylation, dual methylation and methylenedioxy bridge formation [79]. Of the total $63 \mathrm{MTs}$ identified, $18 \mathrm{MTs}$ exhibited differential modulation by two fold and above (Additional file 13) wherein $2 \mathrm{MTs}$ showed up-regulation, and 16 showed down-regulation at $15^{\circ} \mathrm{C}$ as compared to at $25^{\circ} \mathrm{C}$ (Additional file 15). Deeper analysis of these MTs could be promising to identify the genes associated with podophyllotoxin biosynthesis.

Glycosyltransferases (GTs) are super family of enzymes that catalyze transfer of sugars to a wide range of acceptor molecules. Glycosylation of natural products is generally catalyzed by UGTs of family 1 GTs [96]. In higher plants, UGT superfamily glycosylates a broad array of aglycones including plant hormones, plant secondary metabolites and xenobiotics such as herbicides [97]. Glycosylation contributes to increased water solubility, chemical stability and reduced chemical activity and thus plays a role in cell homeostasis, plant growth, development and in response to abiotic stress. Hydroxylated molecules are the common acceptors, while UDP-glucose is the most common donor in the GT catalyzed glycosyl group transferring reaction.

In the lignin biosynthesis pathway, lignin monomers like coumaryl, coniferyl alcohol and sinapyl alcohol are translocated in the form of glucosides from cytosol to cell wall. Involvement of UGTs in the biosynthesis of lignin was also reported [98]. Enzyme activity is expected to be essential for vacuolar storage of otherwise toxic lignans and is shown to be correlated with lignan glucoside accumulation. A podophyllotoxin-glucose glucosidase has been isolated from Podophyllum peltatum [99]. Thus it would be relevant to identify the UGTs involved in enzymatic synthesis of valuable glycoconjugates. BLAST search identified 35 unigenes encoding GTs. A total of 10 UGTs (Additional file 16) exhibited modulation by two fold and above at the two temperatures as analysed through FPKM (Additional file 13), of which 8 UGTs were down-regulated while 2 UGTs showed up-regulation at $15^{\circ} \mathrm{C}$ as compared to $25^{\circ} \mathrm{C}$. In depth analysis of these modulated UGTs would be needed to identify the possible candidates associated with podophyllotoxin biosynthesis.

FPKM based expression values of the selected genes were also validated by qRT-PCR. These genes were ShCYP-7, ShCYP-15, ShCYP-23, ShMTS-6, ShMTS-9 


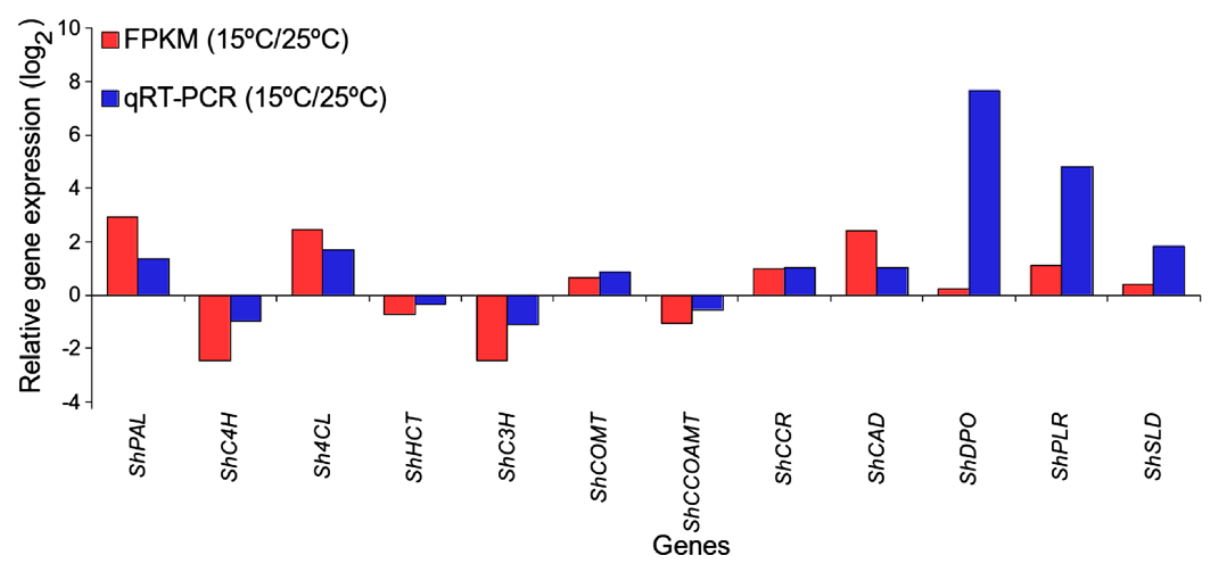

Figure 9 Relative expression of genes associated with podophyllotoxin biosynthesis at $15^{\circ} \mathrm{C}$ relative to at $25^{\circ} \mathrm{C}$. Changes in the abundance of transcripts were analyzed by fragments per kilobase of exon per million fragments mapped (FPKM) as well as quantitative reverse transcriptase-polymerase chain reaction (qRT-PCR). Name of each gene starts with a prefix Sh that stands for Sinopodophyllum hexandrum. Correlation coefficient of FPKM and qRT-PCR was 0.740 ( $p$-value $=0.009$ ). Actin was used as an internal control and each value represents average of three separate biological replicates. Full name of genes, FPKM data, primers and qRT-PCR condition are given in Additional file 2 , Sheet 2.

and ShUGT-6 (Additional file 2). ShCYP-7, and ShCYP-15 were up-regulated, whereas ShCYP-23, ShMTS-6, ShMTS-9; and ShUGT-6 were down-regulated at $15^{\circ} \mathrm{C}$ over $25^{\circ} \mathrm{C}$. FPKM and qRT-PCR based expression data was in accordance with each other (Figure 10) with correlation coefficient of 0.884 ( $\mathrm{p}$-value $=0.0194$ ) suggesting a significant agreement between the expression patterns observed through the two different platforms $[64,65]$.

\section{Conclusion}

The present work analysed temperature $\left(15^{\circ} \mathrm{C}\right.$ and $\left.25^{\circ} \mathrm{C}\right)$ responsive transcriptome of rhizomatous tissue of medicinally important endangered species $S$. hexandrum. A total of 60,089 assembled sequences, representing 20,387 unique genes were obtained on Illumina platform. Assembly of unigenes was validated by full-length sequence data of the available genes of $S$. hexandrum, which showed correct assembly. Transcriptome had an average coverage of $88.34 \mathrm{X}$, average length of $543.11 \mathrm{bp}$, average GC content of $44.59 \%$ and abundance of trinucleotide SSR (54.40\%).

Functional annotation and classification of the $S$. hexandrum transcriptome revealed metabolic process, response to stimulus, cellular process and multicellular organismal development to be the highly represented groups, suggesting rhizome to be metabolically active tissue.

FPKM data was validated by qRT-PCR data and the two platforms of gene expression showed significantly positive correlation emphasizing the confidence in the two different methods of gene expression. Data showed over-expression of genes and TFs associated with growth and development at $15^{\circ} \mathrm{C}$, whereas those associated with stress tolerance over-expressed at $25^{\circ} \mathrm{C}$. Also, various genes involved in podophyllotoxin biosynthesis were identified and their expression both by FPKM and the qRT-PCR showed up-regulation of eight out of twelve genes at $15^{\circ} \mathrm{C}$. Interestingly, podophyllotoxin accumulation also showed increased trend of accumulation at $15^{\circ} \mathrm{C}$. In-depth analyses of CYPS, MTS and UGTs yielded the potential candidate




hitherto unidentified genes of podophyllotoxin biosynthesis. Data generated in the present work will contribute to future studies in the field of functional genomics and metabolic engineering for this important plant species. It will also be worthwhile to analyse microRNAs (miRNAs) because of their role in regulating gene expression either by blocking the process of translation or breaking the target transcripts [100]. MiRNAs are core regulatory component defining spatio-temporal states and are involved in stress responses as well. Challenge would be to analyse miRNAs in this species since its genome sequence is not yet reported [101].

\section{Availability of supporting data}

Raw read files used for assembly were submitted to Short Read Archive (SRA) at NCBI under the accession ID SRX682844 (http://www.ncbi.nlm.nih.gov/sra/ ?term=SRX682844). Transcriptome sequences were submitted to Transcriptome Shotgun Assembly (TSA) project and deposited at DDBJ/EMBL/GenBank under the accession ID GBJY00000000 [http://www.ncbi.nlm.nih.gov/nuccore/ GBJY00000000. The version described in this paper is the first version, GBJY01000000 (http://www.ncbi.nlm. nih.gov/Traces/wgs/?val=GBJY01)]. Sequences, which were less than $200 \mathrm{bp}$ long or had a long stretch of "N" (>14 nucleotides) were not accepted by TSA. These sequences along with submitted sequences can be accessed at http://scbb.ihbt.res.in/Podo-12-12-11/.

\section{Additional files}

Additional file 1: Leaf morphology of $S$. hexandrum grown at $10^{\circ} \mathrm{C}$, $15^{\circ} \mathrm{C}, 25^{\circ} \mathrm{C}$ and $35^{\circ} \mathrm{C}$ for 21 days.

Additional file 2: Details on fragments per kilobase of exon per million fragments mapped (FPKM) values, and oligonucleotide sequences/primers, reaction conditions used in quantitative real-time polymerase chain reaction (qRT-PCR) for genes involved in growth, development and stress response (Sheet 1), podophyllotxin biosynthesis (Sheet 2), and selected cytochrome P450 (CYPs), methyltransferases (MTs) and UDP-glycosyltransferase (UGT) (Sheet 3).

Additional file 3: Effect of k-mer size on assembling performance of transcriptome.

Additional file 4: Top 15 conserved domains identified by RPS-BLAST in S. hexandrum transcriptome.

Additional file 5: List of scaffolds belonging to the different groups after dissimilar clustering step.

Additional file 6: Blast hit of unigenes involved in podophyllotoxin biosynthesis pathway against already submitted coding sequences in GenBank.

Additional file 7: Guanine-cytosine (GC) content (A) and simple sequence repeats (SSRs) (B) identified in transcriptome of S. hexandrum.

Additional file 8: Gene Ontology (GO) classification for $S$. hexandrum transcripts in cellular component, molecular function and biological process categories.

Additional file 9: Functional characterization and abundance of S. hexandrum transcriptome for enzyme classes (A), and Kyoto Encyclopedia of Genes and Genomes (KEGG) pathways (B).
S. hexandrum transcripts were classified in top 50 abundant enzyme classes and KEGG pathways.

Additional file 10: Number of contigs in different Functional Catalogue (FunCat) categories at $15^{\circ} \mathrm{C}$ and $25^{\circ} \mathrm{C}$

Additional file 11: Transcription factor (TF) families identified in S. hexandrum transcriptome.

Additional file 12: Fragments per kilobase of exon per million fragments mapped (FPKM) based expression of transcription factors (TFs) identified in S. hexandrum transcriptome at $15^{\circ} \mathrm{C}$ and $25^{\circ} \mathrm{C}$.

Additional file 13: Fragments per kilobase of exon per million fragments mapped (FPKM) based expression analysis of cytochrome P450s (CYPs, Sheet 1), methyltransferases (MTs, Sheet 2) and uridine diphosphate glycosyltransferases (UGTs, Sheet 3 ) in S. hexandrum transcriptome.

Additional file 14: Fragments per kilobase of exon per million fragments mapped (FPKM) based expression analysis of cytochrome P450s (CYPs) in S. hexandrum transcriptome. Expression of 39 CYPS was studied at $15^{\circ} \mathrm{C}$ and $25^{\circ} \mathrm{C}$. Details of the corresponding contigs listed in Additional file 13.

Additional file 15: Fragments per kilobase of exon per million fragments mapped (FPKM) based expression analysis of methyltransferases (MTs) in S. hexandrum transcriptome. Expression of $18 \mathrm{MTs}$ was studied at $15^{\circ} \mathrm{C}$ and $25^{\circ} \mathrm{C}$. Details of the corresponding contigs are listed in Additional file 13.

Additional file 16: Fragments per kilobase of exon per million fragments mapped (FPKM) based expression analysis of uridine diphosphate glycosyltransferases (UGTs) in S. hexandrum transcriptome. Expression of 10 UGTs was studied at $15^{\circ} \mathrm{C}$ and $25^{\circ} \mathrm{C}$. Details of the corresponding contigs are listed in Additional file 13.

\section{Competing interests}

The authors declare that they have no competing interests.

\section{Authors' contributions}

AK performed experiment at $15^{\circ} \mathrm{C}$ and $25^{\circ} \mathrm{C}$, prepared CDNA library, measured podophyllotoxin content, performed qRT-PCR analysis and did initial drafting of the manuscript. HRS performed the initial computational work and did initial drafting of the manuscript. MKS performed sequencing run on Illumina platform. AJ performed computational analyses for metabolic networks and pathways, FunCat, GO and FPKM based expressions. RS developed the computational analysis protocol, basic analysis codes and planned, designed and supervised the study for computational analysis, and drafted the manuscript. SK conceived the study, designed the experiment, guided wet lab work, interpreted and integrated computational and wet lab results, coordinated the study, drafted and finalized the manuscript. All authors have read and approved the manuscript.

\section{Acknowledgment}

Authors thank the Director, CSIR-IHBT for providing necessary facilities for research. AK is thankful to CSIR for senior research fellowship, HRS and AJ are thankful to CSIR for assistantship. The work represents IHBT communication number 2375.

\section{Funding}

The work was supported by the Council of Scientific and Industrial Research (CSIR), India through the projects entitled "Pathway engineering and system biology approach towards homologous and heterologous expression of high-value phytoceuticals (artemisinin, picrosides, morphine, withanolides, podophyllotoxin (NWP-008)"; "Plant diversity: studying adaptation biology and understanding/exploiting medicinally important plants for useful bioactives (SIMPLE-BSC 0109)"; "Genomics of medicinal plants and agronomically important traits (PlaGen-BSC 0107)"; and Computational Biology project, entitled "Genomics and informatics solutions for integrating biology" (GENESIS-BSC 0121).

\section{Author details}

'Biotechnology Division, CSIR-Institute of Himalayan Bioresource Technology, PO Box No. 6, Palampur 176 061, Himachal Pradesh, India. ${ }^{2}$ Studio of Computational Biology \& Bioinformatics, CSIR-Institute of Himalayan 
Bioresource Technology, PO Box No. 6, Palampur 176 061, Himachal Pradesh, India. ${ }^{3}$ Academy of Scientific \& Innovative Research, New Delhi, India.

Received: 26 December 2013 Accepted: 17 September 2014 Published: 7 October 2014

\section{References}

1. Shaw JMH: New combinations for the varieties of Sinopodophyllum hexandrum. Hanburyana 2009, 4:33-39.

2. Stähelin HF, von Wartburg A: The chemical and biological route from podophyllotoxin glucoside to etoposide: ninth Cain memorial Award lecture. Cancer Res 1991, 51:5-15.

3. Nadeem M, Palni LMS, Purohit AN, Pandey H, Nandi SK: Propagation and conservation of Podophyllum hexandrum Royle: an important medicinal herb. Biol Conserv 2000, 92:121-129.

4. Giri A, Lakshmi Narasu M: Production of podophyllotoxin from Podophyllum hexandrum: a potential natural product for clinically useful anticancer drugs. Cytotechnology 2000, 34:17-26.

5. You Y: Podophyllotoxin derivatives: current synthetic approaches for new anticancer agents. Curr Pharm Des 2005, 11:1695-1717.

6. Kim E, Donohue K: Local adaptation and plasticity of Erysimum capitatum to altitude: its implications for responses to climate change. J Ecol 2013, 101:796-805.

7. Kushwaha R, Pandey S, Chanda S, Bhattacharya A, Ahuja PS: Temperature dependent growth and emergence of functional leaves: an adaptive mechanism in the seedlings of the western Himalayan plant Podophyllum hexandrum. J Plant Res 2008, 121:299-309.

8. Singh A, Purohit AN: Light and temperature effects on physiological reactions on alpine and temperate populations of Podophyllum hexandrum Royle. J Herbs Spices Med Plants 1997, 5:57-66.

9. Schrader J, Moyle R, Bhalerao R, Hertzberg M, Lundeberg J, Nilsson P, Bhalerao RP: Cambial meristem dormancy in trees involves extensive remodelling of the transcriptome. Plant J 2004, 40:173-187.

10. Derory J, Léger P, Garcia V, Schaeffer J, Hauser MT, Salin F, Luschnig C, Plomion C, Glössl J, Kremer A: Transcriptome analysis of bud burst in sessile oak (Quercus petraea). New Phytol 2006, 170:723-738.

11. Paul A, Kumar S: Responses to winter dormancy, temperature, and plant hormones share gene networks. Funct Integr Genomics 2011, 11:659-664.

12. Gahlan P, Singh HR, Shankar R, Sharma N, Kumari A, Chawla V, Ahuja PS, Kumar S: De novo sequencing and characterization of Picrorhiza kurrooa transcriptome at two temperatures showed major transcriptome adjustments. BMC Genomics 2012, 13:126.

13. Venkataraman K: India's Biodiversity Act 2002 and its role in conservation. Trop Ecol 2009, 50:23-30

14. Bhattacharyya D, Sinha R, Ghanta S, Chakraborty A, Hazra S, Chattopadhyay S: Proteins differentially expressed in elicited cell suspension culture of Podophyllum hexandrum with enhanced podophyllotoxin content. Proteome Sci 2012, 10:34

15. Sultan P, Shawl AS, Abdellah AA, Ramteke PW: Isolation, Characterization and Comparative Study on Podophyllotoxin and Related Glycosides of Podophyllum heaxandrum. Curr Res J Biol Sci 2010, 2:345-351.

16. Marques JV, Kim KW, Lee C, Costa MA, May GD, Crow JA, Davin LB, Lewis $N G$ : Next generation sequencing in predicting gene function in podophyllotoxin biosynthesis. J Biol Chem 2013, 288:466-479.

17. Compound extraction of Podophyllum peltatum [http://uic.edu/pharmacy/ MedPITranscriptome/d_podo_p_3.html]

18. Muoki RC, Paul A, Kumari A, Singh K, Kumar S: An improved protocol for the isolation of RNA from roots of tea (Camellia sinensis (L.) O. Kuntze). Mol Biotechnol 2012, 52:82-88.

19. GenScript real-time PCR primer design [https://www.genscript.com/ ssl-bin/app/primer]

20. Pfaffl WP, Horgan GW, Dempfle L: Relative expression software tool (RESTC) for group-wise comparison and statistical analysis of relative expression results in real-time PCR. Nucleic Acids Res 2002, 30:e36.

21. Li R, Zhu H, Ruan J, Qian W, Fang X, Shi Z, Li Y, Li S, Shan G, Kristiansen K, Li $\mathrm{S}$, Yang H, Wang J, Wang J: De novo assembly of human genomes with massively parallel short read sequencing. Genome Res 2009, 20:265-272.

22. Li W, Godzik A: Cd-hit: a fast program for clustering and comparing large sets of protein or nucleotide sequences. Bioinformatics 2006, 22:1658-1659.
23. UniProt Consortium: Reorganizing the protein space at the Universal Protein Resource (UniProt). Nucleic Acids Res 2011, 40(Database issue):D71-D75.

24. Ashburner M, Ball CA, Blake JA, Botstein D, Butler H, Cherry JM, Davis AP, Dolinski K, Dwight SS, Eppig JT, Harris MA, Hill DP, Issel-Tarver L, Kasarskis A, Lewis S, Matese JC, Richardson JE, Ringwald M, Rubin GM, Sherlock G: Gene ontology: tool for the unification of biology. The Gene Ontology Consortium. Nat Genet 2000, 25:25-29.

25. Ogata H, Goto S, Sato K, Fujibuchi W, Bono H, Kanehisa M: KEGG: Kyoto Encyclopedia of Genes and Genomes. Nucleic Acids Res 1999, 27:29-34

26. Webb EC: International Union of Biochemistry and Molecular Biology. Nomenclature Committee. Enzyme nomenclature: Recommendations of the Nomenclature Committee of the International Union of Biochemistry and Molecular Biology on the nomenclature and classification of enzymes. San Diego: Academic Press; 1992:862.

27. Schmid R, Blaxter ML: annot8r: GO, EC and KEGG annotation of EST datasets. BMC Bioinformatics 2008, 9:180.

28. Pérez-Rodríguez $P$, Riaño-Pachón DM, Corrêa LG, Rensing SA, Kersten B, Mueller-Roeber B: PInTFDB: updated content and new features of the plant transcription factor database. Nucleic Acids Res 2010, 40(Database issue):D822-D827.

29. Ruepp A, Zollner A, Maier D, Albermann K, Hani J, Mokrejs M, Tetko I, Güldener U, Mannhaupt G, Münsterkötter M, Mewes HW: The FunCat, a functional annotation scheme for systematic classification of proteins from whole genomes. Nucleic Acids Res 2004, 32:5539-5545.

30. Lamesch P, Berardini TZ, Li D, Swarbreck D, Wilks C, Sasidharan R, Muller R, Dreher K, Alexander DL, Garcia-Hernandez M, Karthikeyan AS, Lee CH, Nelson WD, Ploetz L, Singh S, Wensel A, Huala E: The Arabidopsis Information Resource (TAIR): improved gene annotation and new tools. Nucleic Acids Res 2012, 40(Database issue):D1202-D1210.

31. Marchler-Bauer A, Lu S, Anderson JB, Chitsaz F, Derbyshire MK, DeWeese-Scott C, Fong JH, Geer LY, Geer RC, Gonzales NR, Gwadz M, Hurwitz DI, Jackson JD, Ke Z, Lanczycki CJ, Lu F, Marchler GH, Mullokandov M, Omelchenko MV, Robertson CL, Song JS, Thanki N, Yamashita RA, Zhang D, Zhang N, Zheng C, Bryant SH: CDD: a Conserved domain database for the functional annotation of proteins. Nucleic Acids Res 2011, 39:225-229.

32. Trapnell C, Pachter L, Salzberg SL: TopHat: discovering splice junctions with RNA-seq. Bioinformatics 2009, 25:1105-1111.

33. Trapnell C, Williams BA, Pertea G, Mortazavi A, Kwan G, van Baren MJ, Salzberg SL, Wold BJ, Pachter L: Transcript assembly and quantification by RNA-Seq reveals unannotated transcripts and isoform switching during cell differentiation. Nat Biotechnol 2010, 28:511-515.

34. MISA Program. [http://pgrc.ipk-gatersleben.de/misa]

35. Zhang P, Dreher K, Karthikeyan A, Chi A, Pujar A, Caspi R, Karp P, Kirkup V, Latendresse M, Lee C, Mueller LA, Muller R, Rhee SY: Creation of a genome-wide metabolic pathway database for Populus trichocarpa using a new approach for reconstruction and curation of metabolic pathways for plants. Plant Physiol 2010, 153:1479-1491.

36. Salick J, Fangb Z, Byg A: Eastern Himalayan alpine plant ecology, Tibetan ethnobotany, and climate change. Global Environ Chang 2009, 19:147-155.

37. Zobayed SM, Afreen F, Kozai T: Temperature stress can alter the photosynthetic efficiency and secondary metabolite concentrations in St. John's wort. Plant Physiol Biochem 2005, 43:977-984

38. Alam MA, Gulati P, Aswini KG, Gyan PM, Pradeep KN: Assessment of genetic diversity among Podophyllum hexandrum genotypes of northwestern Himalayan region for podophyllotoxin production. Indian J Biotechnol 2009, 8:391-399.

39. Chandra S: Effect of altitude on energy exchange characteristics of some alpine medicinal crops from central Himalayas. J Agron Crop Sci 2004, 190:13-20.

40. Altschul SF, Gish W, Miller W, Myers EW, Lipman DJ: Basic local alignment search tool. J Mol Biol 1990, 215:403-410.

41. Vinogradov AE: DNA helix: the importance of being GC-rich. Nucleic Acids Res 2003, 31:1838-1844.

42. Nestor CE, Monckton DG: Correlation of inter-locus polyglutamine toxicity with CAG.CTG triplet repeat expandability and flanking genomic DNA GC content. PLOS One 2011, 6:e28260.

43. Holland JB, Helland SJ, Sharopova N, Rhyne DC: Polymorphism of PCR-based markers targeting exons, introns, promoter regions, and SSRs in maize and introns and repeat sequences in oat. Genome 2001, 44:1065-1076.

44. Musashi $\mathrm{M}$, Ota $\mathrm{S}$, Shiroshita $\mathrm{N}$ : The role of protein kinase $\mathrm{C}$ isoforms in cell proliferation and apoptosis. Int J Hematol 2000, 72:12-19. 
45. Annadurai RS, Jayakumar V, Mugasimangalam RC, Katta MA, Anand S, Gopinathan S, Sarma SP, Fernandes SJ, Mullapudi N, Murugesan S, Rao SN: Next generation sequencing and de novo transcriptome analysis of Costus pictus D. Don, a non-model plant with potent anti-diabetic properties. BMC Genomics 2012, 13:663.

46. Smith IK, Polle A, Rennenberg H: Glutathione. In Stress Responses in Plants. Adaptation and Acclimation Mechanisms. Edited by Alscher RG, Cumming JR. New York: Wiley Liss Inc; 1992:201-215.

47. Vu JCV, Allen LH Jr, Gesch RW: Up-regulation of photosynthesis and sucrose metabolism enzymes in young expanding leaves of sugarcane under elevated growth $\mathrm{CO}_{2}$. Plant Sci 2006, 171:123-131

48. An D, Yang J, Zhang P: Transcriptome profiling of low temperature treated cassava apical shoots showed dynamic responses of tropical plant to cold stress. BMC Genomics 2012, 13:64.

49. Hotton SK, Callis J: Regulation of cullin RING ligases. Annu Rev Plant Biol 2008, 59:467-489.

50. TAIR [https://www.arabidopsis.org/servlets/TairObject?name= AT3G12670\&type=locus]

51. Henriksson $E$, Olsson AS, Johannesson $H$, Johansson $H$, Hanson J, Engström $P$, Söderman E: Homeodomain leucine zipper class I genes in Arabidopsis. Expression patterns and phylogenetic relationships. Plant Physiol 2005, 139:509-518

52. Ha CM, Jun JH, Nam HG, Fletcher JC: BLADE-ON-PETIOLE1 encodes a BTB/POZ domain protein required for leaf morphogenesis in Arabidopsis thaliana. Plant Cell Physiol 2004, 45:1361-1370.

53. Jofuku KD, den Boer BG, Van Montagu M, Okamuro JK: Control of Arabidopsis flower and seed development by the homeotic gene APETALA2. Plant Cell 1994, 6:1211-1225.

54. Samach A, Onouchi H, Gold SE, Ditta GS, Schwarz-Sommer Z, Yanofsky MF, Coupland G: Distinct roles of CONSTANS target genes in reproductive development of Arabidopsis. Science 2000, 288:1613-1616.

55. Kim WC, Reca IB, Kim Y, Park S, Thomashow MF, Keegstra K, Han KH: Transcription factors that directly regulate the expression of CSLA9 encoding mannan synthase in Arabidopsis thaliana. Plant Mol Biol 2014 84:577-587.

56. Apuya NR, Yadegari R, Fischer RL, Harada JJ, Zimmerman JL, Goldberg RB: The Arabidopsis embryo mutant schlepperless has a defect in the chaperonin-60alpha gene. Plant Physiol 2001, 126:717-730.

57. Davletova S, Schlauch K, Coutu J, Mittler R: The zinc-finger protein Zat12 plays a central role in reactive oxygen and abiotic stress signaling in Arabidopsis. Plant Physiol 2005, 139:847-856

58. Polidoros AN, Mylona PV, Pasentsis K, Scandalios JG, Tsaftaris AS: The maize alternative oxidase 1a (Aox1a) gene is regulated by signals related to oxidative stress. Redox Rep 2005, 10:71-78.

59. Diédhiou CJ, Popova OV, Dietz KJ, Golldack D: The SNF1-type serine-threonine protein kinase SAPK4 regulates stress-responsive gene expression in rice. BMC Plant Biol 2008, 8:49.

60. Wang W, Vinocur B, Shoseyov O, Altman A: Role of plant heat-shock proteins and molecular chaperones in the abiotic stress response. Trends Plant Sci 2004, 9:244-252.

61. Mizoi J, Shinozaki K, Yamaguchi-Shinozaki K: AP2/ERF family transcription factors in plant abiotic stress responses. Biochim Biophys Acta 2012, 1819:86-96.

62. Yi Y, Guerinot ML: Genetic evidence that induction of root Fe(III) chelate reductase activity is necessary for iron uptake under iron deficiency. Plant J 1996, 10:835-844

63. Sun S, Yu JP, Chen F, Zhao TJ, Fang XH, Li YQ, Sui SF: TINY, a dehydration-responsive element (DRE)-binding protein-like transcription factor connecting the DRE- and ethylene-responsive element-mediated signaling pathways in Arabidopsis. J Biol Chem 2008, 283:6261-6271

64. Wang J, Chen L, Huang S, Liu J, Ren X, Tian X, Qiao J, Zhang W: RNA-seq based identification and mutant validation of gene targets related to ethanol resistance in cyanobacterial Synechocystis sp. PCC 6803. Biotechnol Biofuels 2012, 5:89.

65. Xu L, Zhu L, Tu L, Liu L, Yuan D, Jin L, Long L, Zhang X: Lignin metabolism has a central role in the resistance of cotton to the wilt fungus Verticillium dahliae as revealed by RNA-Seq-dependent transcriptional analysis and histochemistry. J Exp Bot 2011, 62:5607-5621.

66. Heim MA, Jakoby M, Werber M, Martin C, Weisshaar B, Bailey PC: The basic helix-loop-helix transcription factor family in plants: a genome-wide study of protein structure and functional diversity. Mol Biol Evol 2003, 20:735-747.

67. Dubos C, Stracke R, Grotewold E, Weisshaar B, Martin C, Lepiniec L: MYB transcription factors in Arabidopsis. Trends Plant Sci 2010, 15:573-581.

68. Bienz M: The PHD finger, a nuclear protein-interaction domain. Trends Biochem Sci 2006, 31:35-40.

69. Tran LS, Nakashima K, Sakuma Y, Simpson SD, Fujita Y, Maruyama K, Fujita M, Seki M, Shinozaki K, Yamaguchi-Shinozaki K: Isolation and functional analysis of Arabidopsis stress-inducible NAC transcription factors that bind to a drought-responsive cis-element in the early responsive to dehydration stress 1 promoter. Plant Cell 2004, 16:2481-2498.

70. Englbrecht CC, Schoof H, Böhm S: Conservation, diversification and expansion of $\mathrm{C} 2 \mathrm{H} 2$ zinc finger proteins in the Arabidopsis thaliana genome. BMC Genomics 2004, 5:39.

71. Jackson DE, Dewick PM: Biosynthesis of Podophyllum lignans-II. Interconversion of aryltetralin lignans in Podophyllum hexandrum. Phytochemistry 1984, 23:1037-1042.

72. Hoffmann L, Maury S, Martz F, Geoffroy P, Legrand M: Purification, cloning and properties of an acyltransferase controlling shikimate and quinate ester intermediates in phenylpropanoid metabolism. J Biol Chem 2003, 278:95-103.

73. Schoch G, Goepfert S, Morant M, Hehn A, Meyer D, Ullmann P, Werck-Reichhart D: CYP98A3 from Arabidopsis thaliana is a 3'-hydroxylase of phenolic esters, a missing link in the phenylpropanoid pathway. J Biol Chem 2001, 276:36566-36574

74. Fraser CM, Chapple C: The phenylpropanoid pathway in Arabidopsis. Arabidopsis Book 2011, 9:e0152.

75. Davin LB, Wang HB, Crowell AL, Bedgar DL, Martin DM, Sarkanen S, Lewis NG: Stereoselective bimolecular phenoxy radical coupling by an auxiliary (dirigent) protein without an active center. Science 1997, 275:362-366.

76. Katayama T, Davin LB, Lewis NG: An extraordinary accumulation of (-)-pinoresinol in cell-free extracts of Forsythia intermedia: evidence for enantiospecific reduction of (+)-pinoresinol. Phytochemistry 1992, 31:3875-3881.

77. Katayama T, Davin LB, Chu A, Lewis NG: Novel benzylic ether reductions in lignan biogenesis in Forsythia intermedia. Phytochemistry 1993, 33:581-591.

78. Umezawa T, Davin LB, Lewis NG: Formation of lignans, (-)-secoisolariciresinol and (-)-matairesinol with Forsythia intermedia cell-free extracts. J Biol Chem 1991, 266:10210-10217.

79. Sakakibara N, Suzuki S, Umezawa T, Shimada M: Biosynthesis of yatein in Anthriscus sylvestris. Org Biomol Chem 2003, 1:2474-2485.

80. Broomhead AJ, Rahman MA, Dewick PM, Jackson DE, Lucas JA: Matairesinol as precursor of Podophyllum lignans. Phytochemistry 1991, 30:1489-1492.

81. Kuhlmann S, Kranz K, Lücking B: Aspects of cytotoxic lignan biosynthesis in suspension cultures of Linum nodiflorum. Phytochem Rev 2002, 1:37-43.

82. Kamil WM, Dewick PM: Biosynthesis of the lignans $\alpha$ - and $\beta$-peltatin. Phytochemistry 1986, 25:2089-2092.

83. van Uden W, Bouma AS, Bracht Waker JF, Middel O, Wichers HJ, Waard PD, Woerdenbag HJ, Kellogg RM, Pras N: The production of podophyllotoxin and its 5-methoxy derivative through bioconversion of cyclodextrin complexed deoxy-podophyllotoxin by plant cell cultures. Plant Cell Tissue Organ Cult 1995, 42:73-79.

84. van Uden W, Bos JA, Boeke GM, Woerdenbag HJ, Pras N: The large-scale isolation of deoxypodophyllotoxin from rhizomes of Anthriscus sylvestris followed by its bioconversion into 5-methoxypodophyllotoxin $\beta$-d-glucoside by cell cultures of Linun flavum. J Natural Prod 1997, 60:401-403.

85. Yousefzadi M, Sharifi M, Behmanesh M, Moyano E, Bonfill M, Cusido RM, Palazon J: Podophyllotoxin: current approaches to its biotechnological production and future challenges. Eng Life Sci 2010, 10:281-292.

86. Singh K, Rani A, Paul A, Dutt S, Joshi R, Gulati A, Ahuja PS, Kumar S: Differential display mediated cloning of anthocyanidin reductase gene from tea (Camellia sinensis) and its relationship with the concentration of epicatechins. Tree Physiol 2009, 29:837-846.

87. Kawoosa T, Singh H, Kumar A, Sharma SK, Devi K, Dutt S, Vats SK, Sharma M, Ahuja PS, Kumar S: Light and temperature regulated terpene biosynthesis: hepatoprotective monoterpene picroside accumulation in Picrorhiza kurrooa. Funct Integr Genomics 2010, 10:393-404

88. Kumar H, Singh K, Kumar S: 2C-methyl-d-erythritol-2,4-cyclodiphosphate synthase from Stevia rebaudiana Bertoni is a functional gene. Mol Biol Rep 2012, 12:10971-10978.

89. Singh RS, Gara RK, Bhardwaj PK, Kaachra A, Malik S, Kumar R, Sharma M, Ahuja PS, Kumar S: Expression of 3-hydroxy-3-methylglutaryl-CoA 
reductase, $\mathrm{p}$-hydroxybenzoate-m-geranyltransferase and genes of phenylpropanoid pathway exhibits positive correlation with shikonins content in arnebia [Arnebia euchroma (Royle) Johnston]. BMC Mol Biol 2010, 11:88.

90. Schuler MA: Plant cytochrome P450 monooxygenases. Crit Rev Plant Sci 1996, 15:235-284.

91. Federolf K, Alfermann AW, Fuss E: Aryltetralin-lignan formation in two different cell suspension cultures of Linum album: Deoxypodophyllotoxin 6-hydroxylase, a key-enzyme in the formation of 6-methoxypodophyllotoxin. Phytochemistry 2007, 68:1397-1406.

92. Lam KC, Ibrahim RK, Behdad B, Dayanandan S: Structure, function, and evolution of plant O-methyltransferases. Genome 2007, 50:1001-1013.

93. Lewis NG, Yamamoto E: Lignin: occurrence, biogenesis and biodegradation. Annu Rev Plant Physiol Plant Mol Biol 1990, 41:455-496.

94. Boerjan W, Ralph J, Baucher M: Lignin biosynthesis. Annu Rev Plant Biol 2003, 54:519-546.

95. Zhong R, Morrison WH III, Himmelsbach DS, Poole FL II, Ye ZH: Essential role of caffeoyl coenzyme A O-methyltransferase in lignin biosynthesis in woody poplar plants. Plant Physiol 2000, 124:563-578

96. Ross J, Li Y, Lim E, Bowles DJ: Higher plant glycosyltransferases. Genome Biol 2001, 2:REVIEWS3004.

97. Vogt $T$, Jones $\mathrm{P}:$ Glycosyltransferases in plant natural product synthesis: characterization of a supergene family. Trends Plant Sci 2000, 5:380-386.

98. Wang J, Hou B: Glycosyltransferases: key players involved in the modification of plant secondary metabolites. Front Biol China 2009, 4:39-46.

99. Berim A, Ebel R, Schneider B, Petersen M: UDP-glucose:(6-methoxy) podophyllotoxin 7-0-glucosyltransferase from suspension cultures of Linum nodiflorum. Phytochemistry 2008, 69:374-381.

100. Jha A, Mehra M, Shankar R: The regulatory epicenter of miRNAs. J Biosci 2011, 36:621-638.

101. Jha A, Shankar R: miReader: Discovering novel miRNAs in species without sequenced genome. PLoS One 2013, 8:e66857.

doi:10.1186/1471-2164-15-871

Cite this article as: Kumari et al:: Transcriptome sequencing of rhizome tissue of Sinopodophyllum hexandrum at two temperatures. BMC Genomics 2014 15:871.

\section{Submit your next manuscript to BioMed Central and take full advantage of:}

- Convenient online submission

- Thorough peer review

- No space constraints or color figure charges

- Immediate publication on acceptance

- Inclusion in PubMed, CAS, Scopus and Google Scholar

- Research which is freely available for redistribution 